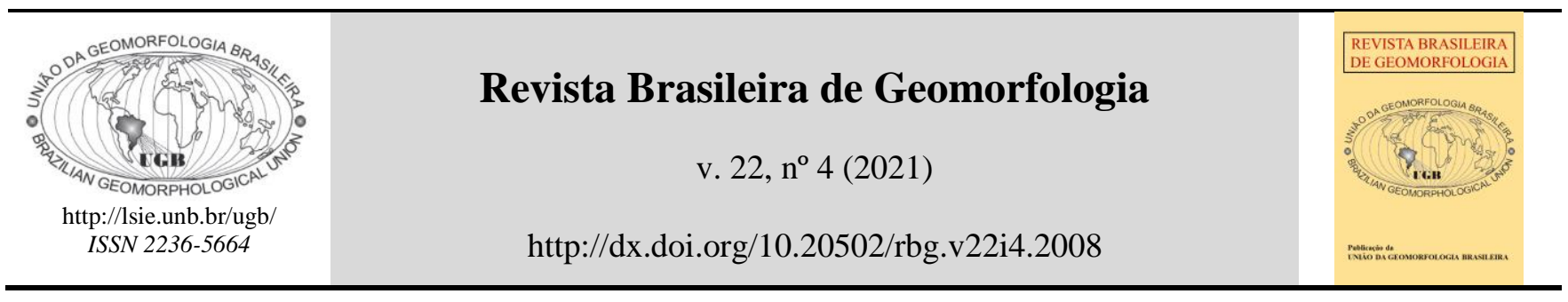

Artigo de Pesquisa

\title{
Efeitos da vegetação na modelagem de estabilidade de encostas na bacia hidrográfica do rio Cunha, Santa Catarina
}

\section{Vegetation effects on slope stability modeling in Cunha river watershed, Santa Catarina}

Gean Paulo Michel', Masato Kobiyama², Roberto Fabris Goerl ${ }^{3}$, Franciele Zanandrea4, Leonardo Rodolfo Paul5, Heron Schwarz ${ }^{6}$ e Gabriel Lopes Cardozo

1 Instituto de Pesquisas Hidráulicas (IPH), Universidade Federal do Rio Grande do Sul, Porto Alegre, RS, Brasil. gean.michel@ufrgs.br ORCID: http://orcid.org/0000-0002-7857-1941

2 Instituto de Pesquisas Hidráulicas (IPH), Universidade Federal do Rio Grande do Sul, Porto Alegre, RS, Brasil. masato.kobiyama@ufrgs.br ORCID: http://orcid.org/0000-0003-0615-9867

3 Universidade Federal de Santa Catarina, Florianópolis, SC, Brasil. roberto.fabris@gmail.com ORCID: http://orcid.org/0000-0001-6261-7143

4 Instituto de Pesquisas Hidráulicas (IPH), Universidade Federal do Rio Grande do Sul, Porto Alegre, RS, Brasil. franciele.zanan@gmail.com ORCID: http://orcid.org/0000-0002-4797-1379

5 Instituto de Pesquisas Hidráulicas (IPH), Universidade Federal do Rio Grande do Sul, Porto Alegre, RS, Brasil. leonardorpaul@gmail.com ORCID: http://orcid.org/0000-0001-5104-5944

6 Instituto de Pesquisas Hidráulicas (IPH), Universidade Federal do Rio Grande do Sul, Porto Alegre, RS, Brasil. heron.sch@gmail.com ORCID: http://orcid.org/0000-0003-1249-8611

7 Instituto de Pesquisas Hidráulicas (IPH), Universidade Federal do Rio Grande do Sul, Porto Alegre, RS, Brasil. gabriel_lopes_cardozo@hotmail.com ORCID: https://orcid.org/0000-0002-4662-0200

Recebido: 01/09/2020; Aceito: 16/03/2021; Publicado: 01/10/2021

Resumo: Os escorregamentos são processos naturais que podem trazer diversos impactos ambientais, sociais e econômicos. A identificação e mapeamento de áreas suscetíveis a escorregamentos são procedimentos importantes no gerenciamento de bacias hidrográficas. O uso de modelos de estabilidade de encostas auxilia na gestão da problemática envolvendo os escorregamentos, mas frequentemente negligenciam o efeito da vegetação. Este trabalho apresenta uma metodologia para analisar o efeito da vegetação em modelos de estabilidade de encostas. Em primeiro lugar, parâmetros relacionados a vegetação foram inseridos no equacionamento do Fator de Segurança (FS). A partir de análise de sensibilidade, verificou-se quais parâmetros possuem maior influência na estabilidade. Posteriormente, o modelo SHALSTAB foi modificado, inserindo os parâmetros mais relevantes, e aplicado na Bacia do rio Cunha. Os efeitos mecânicos, gerados pela presença da vegetação, inseridos na equação do FS são: coesão das raízes $\left(c_{r}\right)$; sobrecarga gerada pelo peso da vegetação $\left(S_{w}\right)$; tensão cisalhante oriunda da ação do vento nas copas das árvores $\left(V_{e}\right)$. Observou-se que cratua no sentido de aumentar a estabilidade da encosta e sua influência é a mais significativa dentre os parâmetros analisados e é maior em solos rasos, diminuindo com o aumento da profundidade. O parâmetro $S_{w}$ atua na redução da estabilidade da encosta e exerce maior influência em solos 
rasos. Já o parâmetro $V_{e}$ apresenta baixa influência sobre o FS e foi desconsiderado na formulação do SHALSTAB. A equação de FS se mostrou sensível a declividade até um ponto mínimo, após este ponto de declividade o FS varia pouco com o aumento da declividade. A análise de sensibilidade do modelo SHALSTAB modificado à variação dos parâmetros de entrada apresentou um comportamento similar àquele demonstrado pelo FS. Assim, a influência da vegetação na variação dos parâmetros e consequentemente na análise de estabilidade demonstrou ser relevante. Desta maneira, a formulação modificada do SHALSTAB proposta pelo presente trabalho pode ser utilizada na análise de estabilidade de encostas com presença de vegetação.

Palavras-chave: Escorregamento de terra; fator de segurança; SHALSTAB; vegetação.

\begin{abstract}
Landslides are natural processes that can cause environmental, social, and economic impacts. The identification and mapping of landslide prone areas are important procedures to watershed management. In this regard, slope stability models can help on these procedures. However, these models frequently neglect the effect of vegetation. This study presents a methodology that considers effects of vegetation in the factor of safety (FS) equation. To this end, parameters related to vegetation effect in slope stability were inserted in SHALSTAB model to verify its influence over landslides occurred in the Cunha River basin. The mechanical effects caused by vegetation added to the FS equation are root cohesion $\left(c_{r}\right)$, overload generated by vegetation weight $\left(S_{w}\right)$ and shear stress caused by wind effects on tree canopy $\left(V_{e}\right)$. Subsequently, we did a sensitivity analysis to identify which parameters have higher influence on the FS, adding the relevant ones to SHALSTAB formulation. We observed that crheightens slope stability and its influence is the most significant among the analyzed parameters, being higher in shallow soils and lower as soil depth increases. Sw reduces slope stability and wields more influence in shallow soils. Ve presented low influence on FS and was not added to SHALSTAB formulation. The FS equation proved to be sensitive on the slope to a minimum point, after this point the $F S$ tends to vary little with the increase in the slope. The sensitivity of SHALSTAB to vegetation parameters was like the FS sensitivity. Thus, the vegetation influence on slope stability analysis proved to be relevant. Therefore, the modified SHALSTAB formulation proposed in this study can be useful to slope stability assessment in vegetated areas.
\end{abstract}

Keywords: Landslides; factor of safety; SHALSTAB; vegetation.

\title{
1. Introdução
}

Os escorregamentos de terra, embora sejam processos naturais modeladores da paisagem, podem trazer inúmeros impactos ambientais, sociais e econômicos. Petley (2012) mostrou que a distribuição espacial dos escorregamentos fatais ao redor do mundo se dá principalmente devido a três fatores: (i) disposição do relevo; (ii) ocorrência de precipitações; e (iii) presença de vítimas em potencial. Estes fatores fazem com que a maior ocorrência destes desastres seja registrada na Ásia (Sul do Himalaia, Índia, Sri Lanka e China entre outros). Porém, há uma crescente ocorrência destes fenômenos na América do Sul, principalmente nos países situados na costa do Oceano Pacífico e no Brasil.

No Brasil, nos últimos anos, os escorregamentos de terra vitimaram centenas de pessoas, sendo que eventos muito significativos ocorreram na região serrana do Rio de Janeiro, em janeiro de 2011 (AVELAR et al., 2013; COELHO NETTO et al., 2013) e no Vale do Itajaí em Santa Catarina em novembro de 2008 (FRANK; SEVEGNANI, 2009). A identificação e mapeamento de áreas suscetíveis a escorregamentos são procedimentos importantes no gerenciamento de bacias hidrográficas. Eles podem contribuir na elaboração de mapas de risco, estimativa de produção de sedimentos e planejamento de medidas estruturais para proteção de infraestruturas (KORUP, 2005). Existem diversos modelos de estabilidade de encostas. A maioria destes considera parâmetros geomorfológicos, geotécnicos e hidrológicos em suas formulações. Este tipo de modelo geralmente é estruturado através da combinação entre equações da mecânica dos solos (equilíbrio limite e fator de segurança) e hidrologia. Entretanto, na maioria das vezes, a influência exercida pela vegetação presente nas encostas não é considerada.

Por muitos anos acreditou-se que a vegetação exercia um papel irrelevante na estabilidade das encostas, entretanto Terzaghi (1950), de maneira qualitativa, já alertava sobre a ocorrência de escorregamentos após o desmatamento das florestas. Posteriormente, diversos autores salientaram a importância da presença de vegetação na estabilidade de encostas (e.g. BISHOP; STEVENS, 1964; TSUKAMOTO; MINEMATSU, 1987; SELBY, 1993). No Brasil, Vianna e Souza (2009) e Marques et al. (2018) indicam maior incidência de escorregamentos em 
áreas com supressão da vegetação nativa. Nos últimos anos, diversos autores têm buscado formas de analisar o efeito da vegetação sobre a estabilidade de maneira mensurável (HWANG et al., 2015; DORREN; SCHWARZ, 2016; COHEN; SCHWARZ, 2017; ROSSI et al., 2017).

A influência da vegetação sobre a estabilidade das encostas pode ser agrupada em duas categorias: (i) mecânica, oriunda da interação entre a vegetação e o solo da encosta; e (ii) hidrológica, advinda da modificação da umidade do solo causada pelas alterações no ciclo hidrológico (GREENWAY, 1987; SIDLE; OCHIAI, 2006). Tratando-se da influência mecânica, destacam-se os efeitos do reforço do solo pela presença das raízes através do aumento da coesão do solo (coesão das raízes) e da ancoragem realizada pelas raízes profundas; da sobrecarga transmitida à encosta devido ao peso das árvores; e da tensão cisalhante transmitida ao solo devido à incidência de vento na copa das árvores.

A coesão das raízes $\left(c_{r}\right)$ vem sendo estudada por diversos autores ao longo dos anos (O'LOUGHLIN, 1974; WU et al., 1979; WATSON et al., 1999; SCHMIDT et al., 2001; ROERING et al., 2003; SAKALS; SIDLE et al., 2004; BAETS et al., 2008; BISCHETTI et al., 2009; JI et al., 2012). As principais conclusões a respeito da resistência das raízes comuns a estes trabalhos são que: (i) individualmente, as raízes de árvores e arbustos podem ter altíssimas resistências à tração (até $75 \mathrm{MN} \cdot \mathrm{m}^{-2}$ para o amieiro); (ii) dentro de uma mesma espécie há uma grande variabilidade na resistência, dependendo do tamanho, idade e condição da raiz e estação do ano; e (iii) o aumento da coesão do solo da encosta proporcionado pelas raízes depende da quantidade de raízes presentes em determinada área.

Além da $c_{r}$, a vegetação das encostas também gera uma sobrecarga devido ao seu peso. Este efeito normalmente é considerado apenas para árvores, já que o peso das pastagens e da vegetação rasteira é relativamente pequeno (STYCZEN; MORGAN, 1995). Embora geralmente considerado um efeito adverso, a sobrecarga gerada pelo peso das árvores pode gerar efeitos benéficos a estabilidade, dependendo da geometria da encosta, da distribuição da vegetação ao longo da encosta e das propriedades do solo (COPPIN; RICHARDS, 1990). Em uma encosta, o peso das árvores aumenta as forças cisalhantes que levam a escorregamentos; em contraponto, há também o incremento das forças normais e na aderência entre as possíveis superfícies de ruptura.

Apesar da ampla discussão acerca do efeito da vegetação na estabilidade de encostas, ainda há divergência quanto à relevância das diferentes influências mecânicas oriundas da presença de vegetação no recorte espacial de bacia. Segundo Rossi et al. (2017), por mais que os efeitos da vegetação sobre a estabilidade sejam bem conhecidos em encostas, o emprego de tais conhecimentos no recorte espacial de bacia é ainda desafiador. A dificuldade decorre de três principais fatores: (a) a falta de dados para a validação de modelos matemáticos; (b) a dificuldade de obtenção e implementação das informações, devido sua variabilidade espacial, e; (c) a complexidade e desconhecimento de processos biofísicos em interação no sistema da paisagem.

Desta maneira, é necessário entender como a vegetação interage com as camadas de solo nas encostas e afeta os processos mecânicos e hidrológicos em escala de bacia. Esta interação pode ser avaliada através da inserção de parâmetros relacionados à vegetação no cálculo do fator de segurança da encosta para diferentes cenários. A verificação da sensibilidade do FS a alguns parâmetros relacionados à vegetação já foi demonstrada por alguns autores (HAMMOND et al., 1992; BORGA et al., 2002). Neste contexto, o presente estudo aprofunda a discussão do tema ao verificar a influência da presença da vegetação na estabilidade das encostas em uma bacia hidrográfica, coberta por floresta ombrófila densa, a partir da aplicação e análise do fator de segurança ( $F S$ ) e do modelo SHALSTAB - Shallow Landsliding Stability Model (DIETRICH; MONTGOMERY, 1998). Para tanto, foram inseridos parâmetros relacionados à presença da vegetação, com posterior aplicação e análise de sensibilidade.

\section{Materiais e Métodos}

A metodologia consiste em duas etapas. A primeira etapa refere-se à inserção dos parâmetros relacionados à presença de vegetação na equação do $F S$, juntamente a uma análise de sensibilidade da formulação proposta. Na segunda etapa os parâmetros considerados relevantes para o equacionamento de $F S$ foram inseridos na formulação do modelo SHALSTAB. A partir disso, o modelo modificado foi aplicado a uma bacia de estudo e realizada sua análise de sensibilidade. 


\subsection{Fator de Segurança (FS)}

O Fator de Segurança (FS) (Eq. (1))' é uma relação muito utilizada para avaliar a probabilidade de ocorrência de falhas em encostas. É expresso pela relação entre a soma das forças resistentes e cisalhantes de uma encosta.

$$
F S=\frac{\text { Somatório das forças resistentes }}{\text { Somatório das forças cisalhantes }}
$$

Desta maneira, quando as forças que promovem a estabilidade são exatamente iguais às forças que promovem a instabilidade, o FS é igual a 1; quando o FS é menor que 1, a encosta está em condição de falha; e quando FS é maior que 1, a encosta está estável. Há uma grande dificuldade em determinar exatamente o valor das forças envolvidas no cálculo de $F S$, portanto não há como assegurar estabilidade absoluta quando $F S$ é maior que 1, apenas um aumento de probabilidade de estabilidade conforme o valor de $F S$ aumenta.

Devido aos diferentes tipos de escorregamentos, o FS pode assumir diversos equacionamentos. Para análise de escorregamentos translacionais, emprega-se a teoria de estabilidade de encostas infinitas (TAYLOR (1948); BISHOP (1955); SELBY, 1993), em que se considera uma possível superfície de ruptura. A profundidade dessa superfície é considerada relativamente pequena comparada ao comprimento da encosta e por isso é chamada de encosta infinita. Há também o pressuposto de que a superfície do lençol freático é paralela à superfície de ruptura e à superfície do solo. Esta superfície de ruptura muitas vezes forma-se em locais onde a água encontra dificuldade para infiltrar verticalmente devido a um alto contraste na condutividade hidráulica. Desta maneira há fluxo lateral, e nestas condições a suposição de fluxo paralelo à superfície torna-se razoável. A Figura 1 mostra um esquema do modelo de encosta infinita.

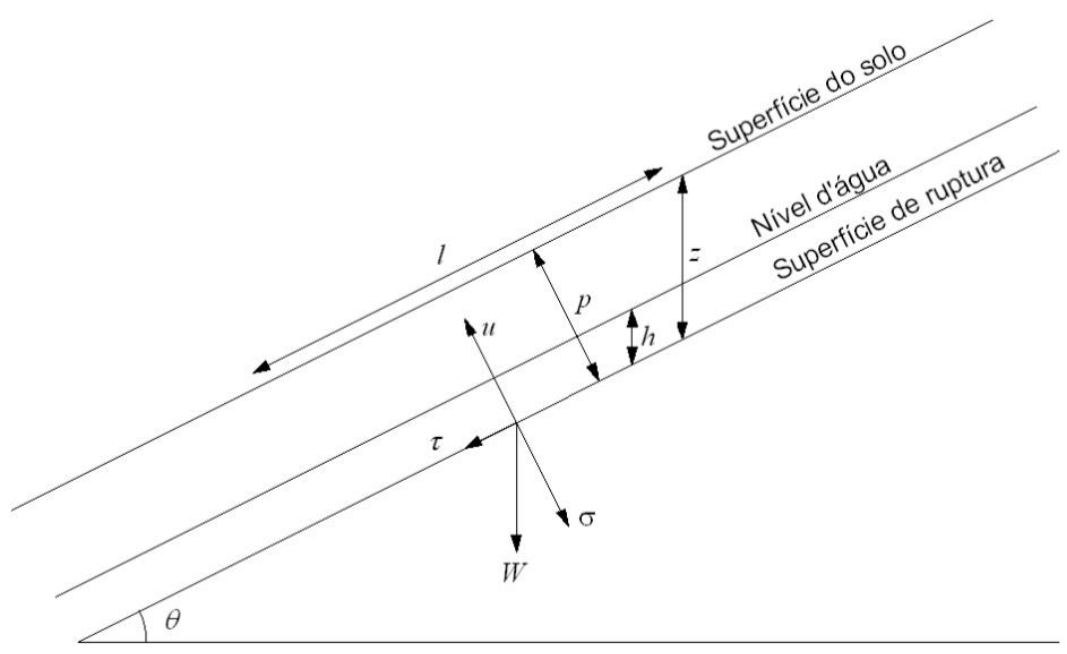

Figura 1. Representação do Modelo de Encosta Infinita.

A formulação do modelo de estabilidade de encosta infinita baseia-se na lei de Mohr-Coulomb em uma abordagem bidimensional, dada por:

$$
\tau=c_{s}+(\sigma-u) \cdot \tan \varphi
$$

onde $\tau$ é a tensão cisalhante no momento da ruptura; $c_{s}$ é a coesão efetiva do solo; $\sigma$ é a tensão normal; $u$ é a poro-pressão; e $\varphi$ é o ângulo de atrito interno efetivo do solo. Assim, o lado esquerdo da equação corresponde às forças cisalhantes e o lado direito às forças resistentes.

\subsection{Inserção dos parâmetros relacionados à vegetação no FS}

Os efeitos mecânicos gerados pela presença da vegetação na estabilidade das encostas inseridos na equação utilizada para cálculo do $F S$ para encostas infinitas são: coesão das raízes $\left(c_{r}\right)$; sobrecarga gerada pelo peso da vegetação $\left(S_{w}\right)$; tensão cisalhante oriunda da ação do vento nas copas das árvores $\left(V_{e}\right)$.

A $c_{r}$ aumenta a resistência pela ligação das fibras das raízes com o solo e cresce com o aumento da concentração de raízes presentes no solo (WU et al., 1979). Essa concentração pode ser representada pela Razão de 
Área de Raízes $(R A R)$. Em geral, a $R A R$ decresce com o aumento da profundidade do solo e da distância até o tronco da árvore (GREENWAY, 1987; BISCHETTI et al., 2005). Portanto, foi adotada uma taxa de decaimento linear da $R A R$ com o aumento da profundidade. Desta maneira, próximo à superfície a $R A R$ é máxima. Ao aproximar-se de 3 metros de profundidade, valor no qual raízes de arbustos de árvores normalmente atingem (COPPIN; RICHARDS, 1990), a RAR tende a zero. Assim, a $c_{r}$ pode ser calculada com base em Wu et al. (1979):

$$
c_{r}=1,2 \cdot T_{r} \cdot R A R
$$

onde $T_{r}$ é a tensão atuante nas raízes (Pa). Assim, a coesão efetiva do solo $\left(c_{s}\right)$ e das raízes podem ser somadas, gerando a coesão total $(C)$.

A $S_{w}$ tem uma componente paralela à encosta $\left(S_{w} \cdot \sin \theta\right)$, a qual favorece o cisalhamento do solo, e uma componente perpendicular à encosta $\left(S_{w} \cdot \cos \theta\right)$, a qual favorece sua estabilização (SELBY, 1993). Já a tensão promovida pela ação do vento na copa das árvores $\left(V_{e}\right)$ irá contribuir para as forças cisalhantes e é calculada seguindo os estudos de Hsi e Nath (1970). Considerando os efeitos de $S_{w}, V_{e}$ e que as tensões cisalhantes e normais dependem do peso do solo e da inclinação da encosta $(\theta)$, $\tau$ e $\sigma$ são expressas pelas Equações 4 e 5 , respectivamente:

$$
\begin{gathered}
\tau=g \cdot \rho_{s} \cdot z \cdot \cos \theta \cdot \sin \theta+S_{w} \cdot \sin \theta+V e \\
\sigma=g \cdot \rho_{s} \cdot z \cdot \cos ^{2} \theta+S_{w} \cdot \cos \theta
\end{gathered}
$$

onde $\rho_{s}$ é a densidade do solo úmido $\left(\mathrm{kg} \mathrm{m}^{-3}\right) ; g$ é a aceleração gravitacional $\left(\mathrm{m} \mathrm{s}^{-2}\right) ; z$ é profundidade vertical do solo (m).

A poro-pressão $(u)$, caracterizada pela pressão a que está submetida a água situada nos poros do solo, atua no sentido de aliviar a tensão normal do solo e pode ser expressa por:

$$
u=g \cdot \rho_{w} \cdot h \cdot \cos ^{2} \theta
$$

onde $\rho_{w}$ é a densidade da água $\left(\mathrm{kg} \mathrm{m}^{-3}\right)$ e $h$ é a altura da coluna d'água dentro da camada de solo $(\mathrm{m})$. Ao inserir a coesão das raízes $\left(c_{r}\right)$, somada a coesão do solo $\left(c_{s}\right)$ e as Equações 4, 5 e 6 na Eq. (2), obtém-se a formulação do FS com consideração de efeitos mecânicos da vegetação:

$$
F S=\frac{c_{s}+c_{r}+\left(g \cdot \rho_{s} \cdot z \cdot \cos ^{2} \theta-g \cdot \rho_{w} \cdot h \cdot \cos ^{2} \theta+S_{w} \cos \theta\right) \cdot \tan \varphi}{g \cdot \rho_{s} \cdot z \cdot \sin \theta \cdot \cos \theta+S_{w} \cdot \sin \theta+V e}
$$

\subsection{Análise de sensibilidade do FS}

A sensibilidade da Eq. (7) à variação dos parâmetros foi conduzida segundo metodologia estabelecida por Hammond et al. (1992) e posteriormente aplicada por Borga et al. (2002). Esta metodologia baseia-se no estabelecimento de valores médios para os parâmetros de entrada, chamados valores centrais $\left(X_{\text {central }}\right.$ e posteriormente na variação de cada parâmetro individualmente, enquanto todos os outros permanecem constantes. A variação dos parâmetros de entrada também gera variação no $F S(\triangle F S)$. Desta maneira, pode-se estabelecer uma hierarquização de sensibilidade do $F S$ à variação dos parâmetros de entrada. A variação do $F S$ e dos parâmetros de entrada são estabelecidas por:

$$
\begin{gathered}
\Delta F S=\frac{F S_{X}-F S_{\text {Xcentral }}}{F S_{\text {Xentral }}} .100 \\
\Delta X=\frac{X-X_{\text {central }}}{X_{\text {central }}} .100
\end{gathered}
$$

onde $X$ é o valor alterado do parâmetro de entrada e $F S_{X}$ é o valor do $F S$ obtido após variação do parâmetro em análise.

\subsection{Modelo SHALSTAB}

O SHALSTAB (DIETRICH; MONTGOMERY, 1998) é um modelo determinístico utilizado na identificação de áreas susceptíveis a escorregamentos translacionais rasos. O SHALSTAB é resultado da associação do modelo de 
encosta infinita, que combina parâmetros geotécnicos e topográficos, com um modelo hidrológico de estado uniforme (O'LOUGHLIN, 1986; BEVEN; KIRKBY, 1979) que utiliza parâmetros geomorfológicos e hidrológicos para estimar o grau de saturação do terreno. $\mathrm{O}$ modelo assume um estado uniforme de recarga que simula o padrão de variação espacial da umidade (altura da coluna d'água) que ocorre durante uma período chuvoso.

O SHALSTAB tem como base o modelo de estabilidade de encostas infinitas solucionando a equação em função de dois parâmetros hidrológicos, $q$ e $T$.

$$
\frac{q}{T}=\frac{b}{a} \cdot \sin \theta \cdot\left\{\frac{\rho_{s}}{\rho_{w}} \cdot\left(1-\frac{\tan \theta}{\tan \varphi^{\prime}}\right)+\frac{C}{\cos ^{2} \theta \cdot \tan \varphi^{\prime} \cdot \rho_{w} \cdot g \cdot z}\right\}
$$

onde $q$ é a taxa de recarga uniforme; $T$ é a transmissividade do solo (produto entre a condutividade hidráulica saturada $\left(K_{s}\right)$ e a espessura saturada do solo $(z)$ ); $a$ é a área de contribuição e $b$ o comprimento de contorno.

Desta maneira, são determinadas classes de estabilidade em função do parâmetro livre q/T. O parâmetro $q / T$ representa a relação entre a taxa de recarga uniforme $(q)$ e a transmissividade do solo $(T)$. A taxa de recarga uniforme expressa a magnitude do evento chuvoso e a transmissividade expressa a capacidade do solo em conduzir o volume de água que está infiltrando. Desta maneira, para uma bacia com características uniformes de transmissividade, quanto maior o valor de $q / T$ calculado pelo modelo, maior é a magnitude do evento chuvoso requerida para gerar instabilidade no terreno. Os valores de $q / T$ são numericamente muito pequenos, por isso são expressos pelo seu logaritmo em base 10. De acordo com Pack et al. (1998), na modelagem de escorregamentos, $q$ não está relacionada com o valor médio da chuva durante um longo período (por exemplo, durante um ano), e sim durante um período crítico de chuva capaz de desencadear escorregamentos.

\subsubsection{Modificações no modelo SHALSTAB}

Baseado na análise de sensibilidade realizada com o $F S$, os parâmetros que geraram influência significativa foram inseridos na formulação do modelo SHALSTAB. Em relação aos efeitos mecânicos da vegetação foram inseridos os parâmetros $c_{r}$ e $S_{w}$. A $V_{e}$ não foi inserida devido à baixa sensibilidade de $F S$ a este parâmetro e à necessidade de uma combinação de determinados eventos para que esta grandeza alcance valores relevantes. Assim, o equacionamento final elaborado no presente trabalho foi similar ao realizado por Borga et al. (2002).

Para inserção dos parâmetros $c_{r}$ e $S_{w}$ no SHALSTAB, o algoritmo utilizado foi reescrito. A classificação da estabilidade é realizada segundo a seguinte equação:

$$
\frac{q}{T}=\frac{b}{a} \cdot \sin \theta \cdot\left\{\left(\frac{\rho_{s}}{\rho_{w}}+\frac{S_{w}}{p_{w} \cdot g \cdot z \cdot \cos \theta}\right) \cdot\left(1-\frac{\tan \theta}{\tan \varphi}\right)+\frac{c_{s}^{\prime}+c_{r}}{\cos ^{2} \theta \cdot \tan \varphi^{\prime} \cdot \rho_{w} \cdot g \cdot z}\right\}
$$

O SHALSTAB, bem como o modelo modificado proposto por este trabalho, estabelece suas classes de estabilidade em função de um parâmetro hidrológico livre: $q / T$. Deste modo é calculado o valor de $q / T$ requerido para que o terreno se torne instável. Além disso, existem duas classes extremas (incondicionalmente instável e incondicionalmente estável) que não dependem das condições hidrológicas para serem estabelecidas. Desta maneira, é necessário determinar um valor para o parâmetro $q / T$ para representar o limiar de estabilidade da bacia. As classes de estabilidade expressam uma probabilidade de ocorrência de escorregamento, sendo que quanto menor o valor de $q / T$, maior a probabilidade de falha da encosta. Para esse estudo utilizou-se 4 classes: incondicionalmente instável; incondicionalmente estável; instável e estável.

Adotando como critério a maior relação entre porcentagem de escorregamentos detectados e porcentagem de área instável, o valor de $\log q / T$ igual a $-3,1$ foi estabelecido como limiar de estabilidade. Desta maneira, a área instável total da bacia foi calculada pela soma da área na classe incondicionalmente instável e onde log $q / T<-3,1$.

Para contemplar a influência da presença da vegetação na variação dos parâmetros hidrológicos, foram aplicados coeficientes de majoração ao parâmetro $K_{s}$ (que serve de base para cálculo de $T$ ) e minoração ao parâmetro $q$. Os coeficientes de majoração e minoração foram estabelecidos com base na amplitude de variação destes parâmetros pela presença de vegetação estabelecida por trabalhos que realizaram tais medições. Assim, admitiu-se que a taxa de recarga do solo $(q)$ pode sofrer uma variação de até $\pm 50 \%$ devido aos fenômenos de interceptação, evapotranspiração e mudanças na taxa de infiltração. Para $K_{s}$ foi admitida uma amplitude de variação de até 200\%. Para Ohta et al. (1985), o valor de $K_{s}$ na modelagem hidrológica pode ser considerado uma ordem de grandeza maior que o valor medido ou estimado. Isto se deve a possível formação de fluxos preferenciais na camada de solo, que aumentarão drasticamente a condutividade real. Desta maneira, para 
obtenção dos valores de $T$, o valor de $K_{s}$ foi majorado dez vezes. A partir do estabelecimento dos valores de $T$, o valor de $q$ foi calculado para que a relação $\log q / T=-3,1$ fosse satisfeita.

Algumas limitações do modelo devem ser consideradas, como na componente geomecânica em que são consideradas apenas as tensões que se estabelecem na área basal da camada de solo e os parâmetros do solo são considerados constantes ao longo da profundidade. Já no modelo hidrológico admite-se uma altura de camada d'água no solo resultante de condição de estado permanente e uniforme de recarga, o que raramente ocorre em eventos intensos, ressaltando que o modelo deve ser usado da perspectiva de adoção de taxas de recarga que sejam capazes de imitar os padrões de saturação gerados pelos eventos intensos.

\subsubsection{Sensibilidade do modelo SHALSTAB}

Para verificação da sensibilidade do modelo à variação dos parâmetros de entrada foi estabelecida a variação percentual da área instável dentro da bacia (Eq. (12)) devido à variação de cada parâmetro. Cada parâmetro foi variado separadamente enquanto os outros permaneciam constantes.

$$
\triangle A I=A I-A I_{\text {central }}
$$

onde $\triangle A I$ é a variação percentual da área instável, $A I$ é a porcentagem da área instável dentro da bacia utilizando determinada combinação de parâmetros e $A I_{\text {central }}$ é a área instável da bacia utilizando o valor central para cada parâmetro.

\subsection{Aplicação na área de estudo}

Em novembro de 2008, diversos municípios de Santa Catarina, principalmente os localizados no Vale do Itajaí, sofreram com a ocorrência de inúmeros escorregamentos e inundações (FRANK; SEVEGNANI, 2009; GOERL et al., 2009a e 2009b; ROCHA et al., 2009; KOBIYAMA et al., 2010), incluindo o município de Rio dos Cedros. Devido à grande ocorrência de escorregamentos na região, optou-se por selecionar uma sub-bacia do município de Rio dos Cedros para aplicação do modelo e análise de sensibilidade em relação aos parâmetros de vegetação. A bacia do rio Cunha foi selecionada porque ocorreram sete escorregamentos de proporções consideráveis em novembro de 2008 (Figura 2a). A bacia do rio Cunha possui uma área de $16,7 \mathrm{~km}^{2}$ e sua altimetria varia de 90 a $860 \mathrm{~m}$.

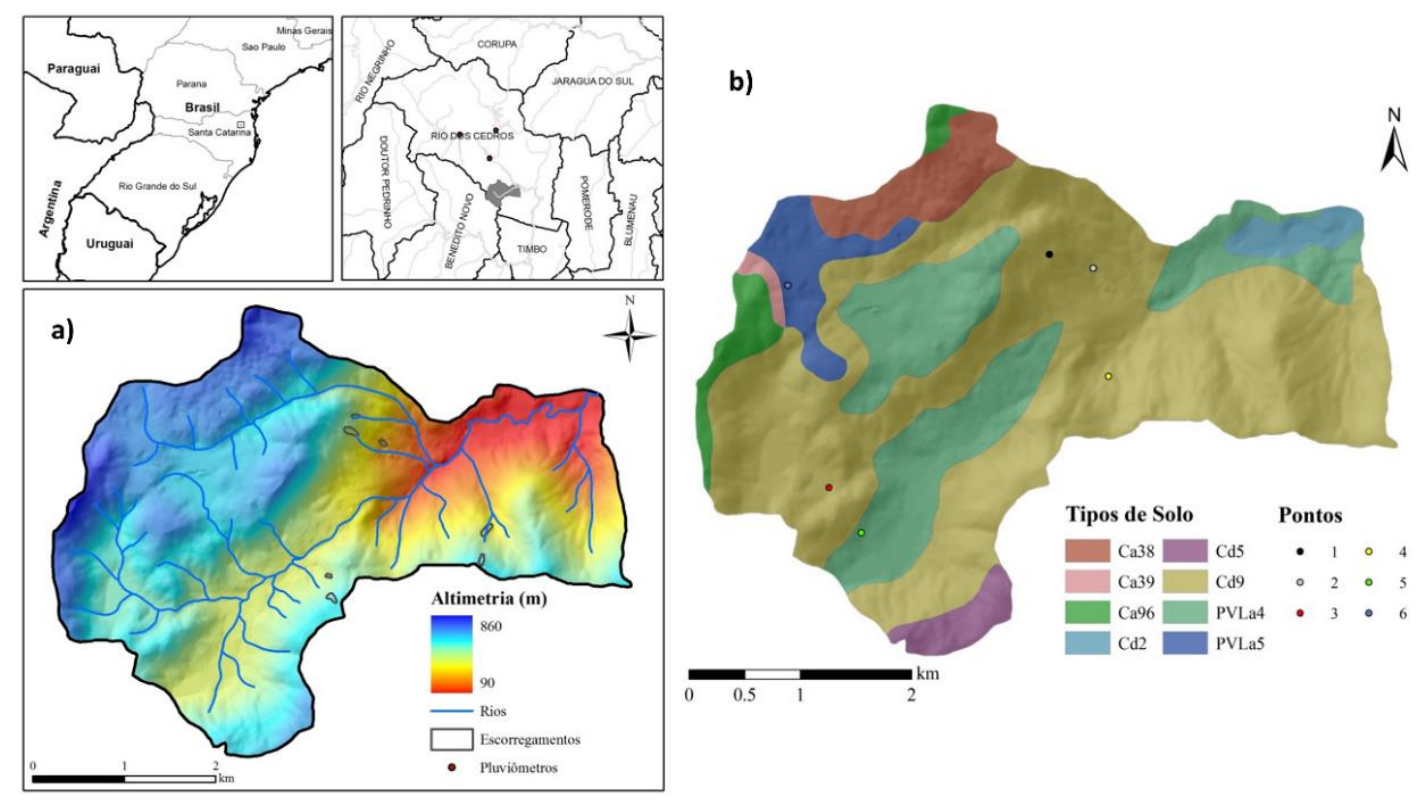

Figura 2. Mapa de a) localização e altimetria e b) tipos de solo da bacia do rio Cunha - SC (IBGE, 2003).

As características pedológicas da bacia exercem grande influência sobre a estabilidade das encostas, já que ditam a resistência ao cisalhamento dos solos e a capacidade de transmitir a água que infiltra durante um período chuvoso. Em relação à pedologia, segundo mapa do IBGE (2003) em Escala 1:250.000, os Cambissolos distróficos, 
eutróficos e álicos (Ca38, Ca39, Ca96, Cd2, Cd5 e Cd9) são predominantes na bacia, ocupando cerca de 75\% da área total da bacia, associado principalmente ao relevo montanhoso. O relevo montanhoso, onde se encontra este tipo de solo, é caracterizado por vales bem encaixados com alta declividade. O Cambissolo Cd9 tem maior predominância na bacia (cerca de $62 \%$ da área total). Este Cambissolo é constituído principalmente de material com textura argilosa. Os diferentes tipos de Argissolo vermelho-amarelo latossólico alumínico (PVLa4 e PVLa5, chamados de Podzólico vermelho-amarelo latossólico álico na antiga classificação) compõem os outros $25 \%$ da bacia. Segundo EMBRAPA (2006), os Cambissolos compreendem solos constituídos por grande heterogeneidade de material mineral, com horizonte B incipiente subjacente a qualquer tipo de horizonte superficial. A classe comporta desde solos fortemente até imperfeitamente drenados, de rasos a profundos, de diversas colorações, de alta a baixa saturação e atividade química de fração da argila. Os Argissolos por sua vez englobam solos com horizonte B textural, normalmente com argila de atividade baixa e ocorrência de argila de atividade alta, conjugada com saturação por bases baixa ou com caráter alítico.

Conforme CPRM (2014), em relação à geologia, a área de estudo se encontra na bacia gnaisse (94\%) e folhelho (6\%). Segundo IBGE (2003), quase a totalidade da bacia está enquadrada dentro do Complexo Luiz Alves, formado por gnaisses granulíticos ortoderivados. A bacia do rio Cunha é uma bacia pouco urbanizada. O solo é predominantemente coberto por mata nativa (cerca de $70 \%$ da área total). A mata nativa está quase sempre associada aos locais com relevo montanhoso e vales encaixados. Segundo Santa Catarina (1986), a vegetação é caracterizada por Floresta Ombrófila Densa, constituinte do bioma Mata Atlântica. Dentro deste ambiente, ocorre a presença de Floresta Montana com vegetação secundária, composta por ervas, arbustos e árvores de pequeno, médio e grande porte. Nas encostas, a vegetação começa com ervas e termina em florestas com elevado estágio sucessional em alto nível de conservação, cujo aspecto fisionômico é muito semelhante à floresta primária. Onde o relevo torna-se mais ameno, há grande incidência de pastagem, segundo maior uso do solo com cerca de $20 \%$ da área total. Há também áreas de monoculturas de Eucalipto e Pinus.

Para aplicação do modelo, foram necessários dados topográficos, hidrológicos e geotécnicos. Os dados topográficos foram obtidos a partir do modelo digital de terreno (MDT) da bacia e do inventário de cicatrizes de escorregamentos realizado. Através do MDT, foram extraídas as informações de $\theta$, direção de fluxo e $a / b$. A resolução do MDT exerce grande influência no processo de modelagem, sendo que MDTs de baixa resolução subestimam a declividade das encostas e diminuem a precisão dos resultados (DIETRICH; MONTGOMERY, 1998; GUIMARÃES et al., 2003). Para a elaboração do MDT, foram utilizadas curvas de nível de intervalo de 5 m, obtidas através do perfilamento digital com o sensor Leica ADS-40. As curvas de nível foram interpoladas pela extensão Topo to Raster do ArcGis, quando foi gerado um raster de grade regular com resolução de $5 \mathrm{~m}$.

O inventário de cicatrizes de escorregamentos, essencial para avaliação do desempenho do modelo, foi elaborado através da análise visual de ortofotos da bacia na escala 1:5000. Além disso, utilizou-se GPS diferencial Trimble R3 e 5700 e estação total Leica TPS-407 para aquisição de pontos de escorregamentos ocorridos na bacia, complementando as informações observadas nas ortofotos. Os dados pedológicos foram obtidos através de coleta de amostras em campo e ensaios realizados em laboratório. Foram realizados ensaios de cisalhamento direto, granulometria e avaliação da densidade do solo.

Para o ensaio de cisalhamento direto foram coletadas dez amostras de solo indeformadas na superfície de ruptura de dois dos escorregamentos da bacia do rio Cunha (pontos de amostragem 1 e 2 na Figura 2b), a uma profundidade média de $2 \mathrm{~m}$. Nestes locais, há a ocorrência do Cambissolo Cd9. Os ensaios de cisalhamento direto foram realizados com base na norma ASTM D3080-04, a uma velocidade de 0,005 $\mathrm{cm} \mathrm{s}^{-1}$. Os ensaios foram realizados em condição saturada, a fim de simular uma condição crítica. Os resultados dos ensaios foram publicados por Reginatto et al. (2012). Como resultado do ensaio de cisalhamento direto obteve-se os parâmetros de $c^{\prime}$ s e $\phi$. Amostras de solo deformadas foram coletadas em quatro diferentes pontos da bacia (pontos de amostragem 3, 4, 5 e 6 na Figura $2 \mathrm{~b}$ ) e a duas profundidades, $50 \mathrm{~cm} \mathrm{e} 1 \mathrm{~m}$. Dois destes pontos foram dispostos em locais onde há ocorrência do Cambissolo Cd9 (pontos 3 e 4 na Figura 2b). Os outros dois pontos, nos Argissolos PVLa4 e PVLa5 (pontos 5 e 6 na Figura 2b). As análises granulométricas foram realizadas pela Companhia Integrada de Desenvolvimento Agrícola de Santa Catarina (CIDASC). Amostras indeformadas adicionais foram coletadas em todos os seis pontos de amostragem para avaliação da densidade do solo. Nos pontos de amostragem 1 e 2, as amostras foram coletadas a $2 \mathrm{~m}$ de profundidade. Nos pontos 3, 4, 5 e 6, as amostras foram coletadas a duas profundidades, $50 \mathrm{~cm}$ e $1 \mathrm{~m}$. Estas amostras foram submetidas à umidificação por capilaridade e 
pesagem, e posterior secagem e pesagem para cálculo da densidade do solo úmido $\left(\rho_{s}\right)$ e densidade do solo seco $(\rho d s)$.

Os dados de granulometria e $\rho_{d s}$ (bulk density) foram utilizados para estimar $K_{s}$. Para realizar esta estimativa foi utilizado o software HYDRUS-1D, modelo Rosetta Lite Version 1.1 (SCHAAP et al., 2001). Este modelo utiliza funções de correlação, ou pedotransferência, para estimativa dos parâmetros hidráulicos do solo. Além disso, observações em campo dos locais onde ocorreram os escorregamentos permitiram realizar uma estimativa de $z$ local. Percebe-se uma variação considerável da profundidade do solo em função da localidade. Nos locais de maior $\theta$, o manto de solo tende a ser mais raso, enquanto em porções menos declivosas há possibilidade de maior acumulação de solo. Nas cabeceiras dos escorregamentos, observam-se valores de $z$ variando de 10 a $15 \mathrm{~m}$, ou seja, abaixo da zona de raízes. Nas zonas de transporte do material movimentado, onde $\theta$ aumenta, percebe-se uma redução da espessura do solo para um valor próximo de $5 \mathrm{~m}$. Os valores médios dos parâmetros medidos e estimados estão apresentados na Tabela 1. Os parâmetros do modelo são considerados constantes em toda a área da bacia.

Tabela 1. Valor médio dos parâmetros medidos e estimados.

\begin{tabular}{cc}
\hline Parâmetro & Valor médio \\
\hline$c_{s}(\mathrm{kPa})$ & 11,9 \\
$\phi\left(^{\circ}\right)$ & 31,2 \\
$\rho_{s}\left(\mathrm{~kg} \mathrm{~m}^{-3}\right)$ & 1750 \\
$K_{s}\left(\mathrm{~cm} \mathrm{dia}^{-1}\right)$ & 45 \\
$z(\mathrm{~m})$ & 10 \\
\hline
\end{tabular}

Para aplicação e análise de sensibilidade do modelo modificado, utilizou-se primeiramente como valor central para os parâmetros de entrada aqueles obtidos a partir de ensaios realizados (Tabela 1). Os parâmetros de entrada que não foram medidos foram estimados através de referências e estão apresentados na Tabela 2. De maneira similar à análise de sensibilidade realizada com o $F S$, foram utilizados quatro valores centrais para $z: 1,2$, 5 e $10 \mathrm{~m}$. Além disso, também foi considerada a redução da $R A R$ com o aumento de $z$.

\section{Resultados e discussão}

\subsection{Análise de Sensibilidade do FS}

Os valores utilizados para os parâmetros da formulação do $F S$ foram determinados a partir de valores da bibliografia (COPPIN; RICHARDS, 1990; WU et al., 1979) e segundo as características levantadas na bacia de estudo. Os valores centrais, mínimos e máximos utilizados para avaliação da sensibilidade do FS estão na Tabela 2 .

Tabela 2. Parâmetros utilizados na análise de sensibilidade do FS.

\begin{tabular}{ccc}
\hline Parâmetro & Valor Central & $\boldsymbol{\Delta} \%$ \\
\hline $\mathcal{C}_{s}(\mathrm{kPa})$ & 12 & $\pm 100 \%$ \\
$\phi\left(^{\circ}\right)$ & 30 & $\pm 70 \%$ \\
$\rho_{s}\left(\mathrm{~kg} \mathrm{~m}^{-3}\right)$ & 1750 & $\pm 20 \%$ \\
$z(\mathrm{~m})$ & $1 ; 2 ; 5 ; 10$ & $\pm 100 \%$ \\
$h / z(\%)$ & $50 \%$ & $\pm 100 \%$ \\
$C_{r}(\mathrm{kPa})$ & 10 & $\pm 100 \%$ \\
$S_{w}(\mathrm{kPa})$ & 2,6 & $\pm 100 \%$ \\
$V_{e}(\mathrm{kPa})$ & 0,5 & $\pm 100 \%$ \\
$\theta\left({ }^{\circ}\right)$ & 25 & $-50 ;+100 \%$ \\
\hline
\end{tabular}


A Figura 3 mostra a análise de sensibilidade do FS à variação dos parâmetros para as profundidades de 1, 2, 5 e $10 \mathrm{~m}$, respectivamente. Nota-se que a escolha dos valores centrais é de grande relevância na análise de sensibilidade, pois a influência de cada parâmetro pode ser severamente alterada pela escolha de seu valor central ou do valor central de algum parâmetro correlacionado.
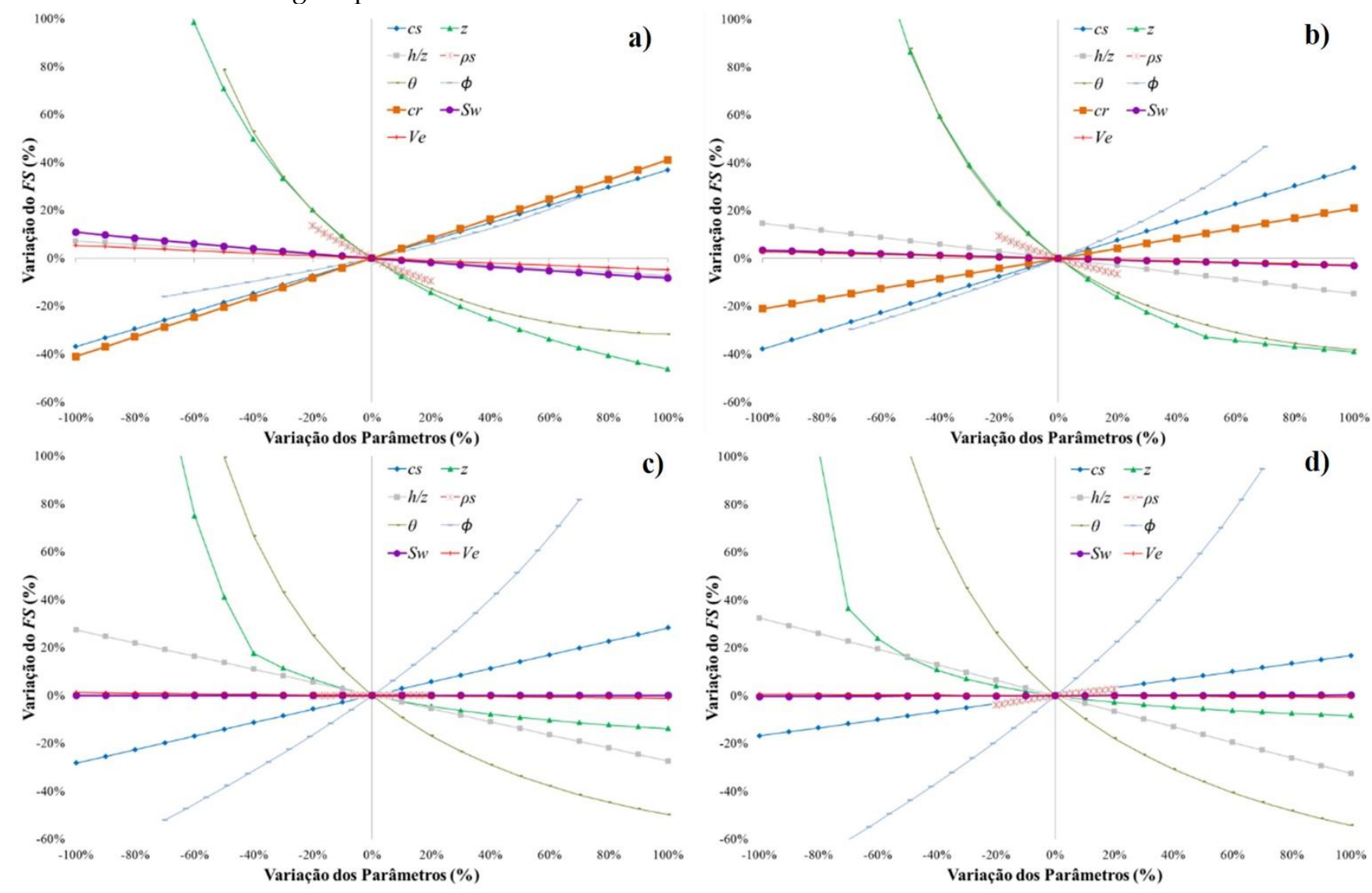

Figura 3. Análise de Sensibilidade do FS (Valor central de z a) $z=1 \mathrm{~m}, \mathrm{~b}) \mathrm{z}=2 \mathrm{~m}, \mathrm{c}) \mathrm{z}=5 \mathrm{~m}$, e d) $z=10 \mathrm{~m}$ ).

Em uma primeira análise observa-se que o aumento da resistência do solo $\left(c_{S}\right.$ e $\left.\phi\right)$ e da contribuição das raízes $\left(c_{r}\right)$ eleva os valores do FS. Em contrapartida, o aumento de $\theta, z, h / z, S_{w}$ e $V_{e}$, reduzem o valor do $F S$. Entretanto, observa-se um padrão indefinido para a $\rho s$, dependente da profundidade utilizada como valor central. Observa-se que a declividade tem grande influência no FS até um certo ponto, onde a partir deste local sua influência diminui, ou seja, o valor de FS tende a estabilizar. A estabilidade da encosta é extremamente dependente de $\theta$, sendo assim, para qualquer profundidade de solo, a correta estimativa da declividade é de grande relevância para seu cálculo, bem como a avaliação da faixa de valores de declividade para qual a equação de FS é válida. Os modelos digitais de terreno (MDT's), vastamente utilizados na modelagem de escorregamentos, podem apresentar deficiências na representação de $\theta$ devido a sua elaboração a partir de mapas com resolução espacial inadequada.

Portanto deve-se atentar às metodologias utilizadas para elaboração do MDT na hipótese de utilização do modelo de encosta infinita. Os termos relacionados à coesão afetam o FS de maneira mais acentuada em solos rasos que em solos espessos. De maneira recíproca, o FS é mais afetado pela variação de $\phi$ interno em solos mais espessos. Esta condição se estabelece porque a resistência devido ao atrito entre as partículas (relacionada a $\phi$ ) eleva-se com o aumento da tensão normal à encosta aplicada pelo peso do solo. Desta maneira, encostas com baixa declividade também contribuem para o aumento da resistência devido ao atrito. A resistência devido às forças coesivas sobressai-se em condições de baixa tensão normal, ou seja, solos rasos e declivosos. Além disso, a pressão de água dos poros gerada pela saturação do solo pode ressaltar a influência das forças coesivas no valor de FS em detrimento das forças oriundas do atrito entre as partículas.

Um efeito similar pode também ser observado pela influência gerada no $F S$ pela variação de $\rho_{s}$. Em solos rasos o aumento de $\rho_{s}$ reduz os valores do FS. Em solos espessos o efeito é contrário, o aumento de $\rho_{s}$ eleva os Revista Brasileira de Geomorfologia. 2021, v. 22, n. 4; (Out-Dez) DOI: 10.20502/rbg.v22i4.2008 http://www.lsie.unb.br/rbg/ 
valores do FS. Há um valor de $z$ para o qual não são computadas variações significativas do $F S$ em função de $\rho_{s}$ (no caso apresentado, este valor aproxima-se dos $5 \mathrm{~m}$ de profundidade). Este valor pode ser considerado um limiar acima do qual o aumento de $\rho_{s}$ passa a ser benéfico para a estabilidade da encosta. Este efeito também é explicado pela relação entre as forças coesivas e de atrito que agem na encosta. Para grandes massas de solo, o aumento do peso total favorece o aumento das forças de atrito e ajuda na estabilização da encosta. Em profundidades pequenas, o aumento do peso do solo reduz a efetividade das forças coesivas, diminuindo a resistência da encosta.

Claramente nota-se a influência direta da variação de $z$ no valor do FS. A profundidade do solo não necessariamente representa a espessura total do material não consolidado. A aplicação mais comum do modelo de encosta infinita se dá em condições de solos rasos dispostos sobre um manto rochoso. Neste caso, $z$ representa a espessura entre o manto rochoso e a superfície. Porém, é comum que planos de ruptura translacionais se formem em fronteiras entre materiais de diferentes condutividades onde há incidência de altos valores de pressão dos poros. Nestes casos, a profundidade de ruptura pode ser muito menor que a espessura existente entre o manto rochoso e a superfície do solo. Por isso, é necessário entender como o FS se comporta ao longo do perfil do solo.

Devido à dependência linear entre $c_{r}$ e $z$ adotada pelo presente trabalho, a sensibilidade do $F S$ à variação de $z$ demonstrou ser muito mais acentuada do que a apresentada por Hammond et al. (1992) e Borga et al. (2002). Esta sensibilidade é ainda mais pronunciada em solos rasos, onde há maior presença de raízes. Em solos com profundidades maiores que $3 \mathrm{~m}$ (profundidade limite na qual foi computada a ação das raízes) a variação de $F S$ devido a $z$ segue dois comportamentos distintos. O primeiro comportamento mostra uma grande sensibilidade do FS e isto ocorre até que $z$ aproxime-se da profundidade limite. A partir da profundidade limite é observado um padrão de variação de $F S$ muito mais ameno. Nestes casos, mesmo não havendo a contribuição de $c_{r}$ para aumento da resistência da encosta a grandes profundidades, a presença das raízes dificulta a formação de superfícies de ruptura nas camadas superiores do solo.

Observa-se que o valor central utilizado para $z$ acaba gerando grandes alterações na sensibilidade do FS a determinados parâmetros. A variação dos parâmetros $\theta, \phi$, e $h / z$, gera maior influência sobre o $F S$ em solos profundos. Em contraponto, a variação de $c_{s}, c_{r}$, $S w$ e $V_{e}$ tem maior influência sobre $F S$ em solos rasos. Observando-se a influência de $\rho_{s}$ sobre $F S$, verifica-se que a uma profundidade de aproximadamente $5 \mathrm{~m}$ não há sensibilidade do $F S$ a este parâmetro. A Figura 4 mostra a amplitude de variação do $F S$ devido à variação dos parâmetros de entrada, dentro dos limites estabelecidos pela Tabela 1, para diferentes valores centrais de $z$.

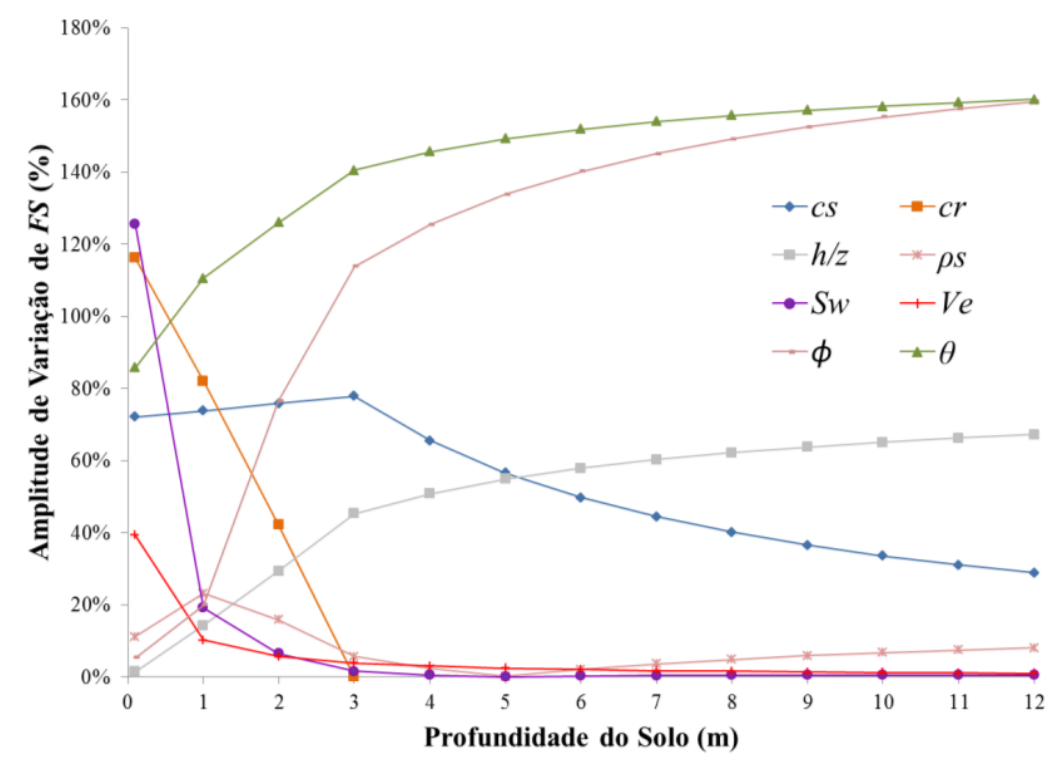

Figura 4. Amplitude de variação do FS devido a variação dos parâmetros de entrada para diversos valores centrais de $z$.

A influência de $z$ no FS ainda depende de outras relações como: (i) existência de forças coesivas no solo e $V_{e}$; e (ii) como a altura da camada d'água dentro do solo $(h)$ é abordada pela análise. A abordagem inicial utilizada pelo presente trabalho traz o pressuposto de que os solos analisados são coesivos e que a parcela saturada do solo se 
mantém constante com o aumento da profundidade. Entretanto, quando estes pressupostos são parcialmente ignorados, observa-se um padrão diferente no comportamento do $F S$ em relação à variação de $z$.

No caso de ausência de forças coesivas e $V_{e}$, algumas observações podem ser feitas. Quando o solo está completamente seco $(h / z=0)$ o FS não varia com o aumento de $z$. Neste caso, as mudanças nas forças que conduzem à instabilidade, originadas pela variação de $z$, são compensadas pelas mudanças nas forças de resistência do solo. O FS simplifica-se à relação entre a tangente de $\phi$ e a tangente de $\theta$, não dependendo assim de z. Quando h/z é mantido constante, o aumento da profundidade do solo causa redução do FS. Quando apenas a altura da camada d'água ( $h$ ) é mantida constante, o aumento de $z$ gera elevação dos valores de FS (Figura 5a). Quando há a existência de forças coesivas na encosta, a influência da variação de $z$ no $F S$ segue um padrão diferente. Quando o solo está seco $(h / z=0)$, o aumento de $z$ reduz o FS. Quando $h / z$ é mantido constante, há uma redução ainda maior do FS com o aumento da profundidade. Entretanto, quando se mantêm constante a altura da coluna d'água, há um valor de $h$ para qual o FS é insensível à variação de $z$. Para valores de $h$ acima deste equilíbrio, o aumento de $z$ gera uma elevação no FS (Figura 5b).
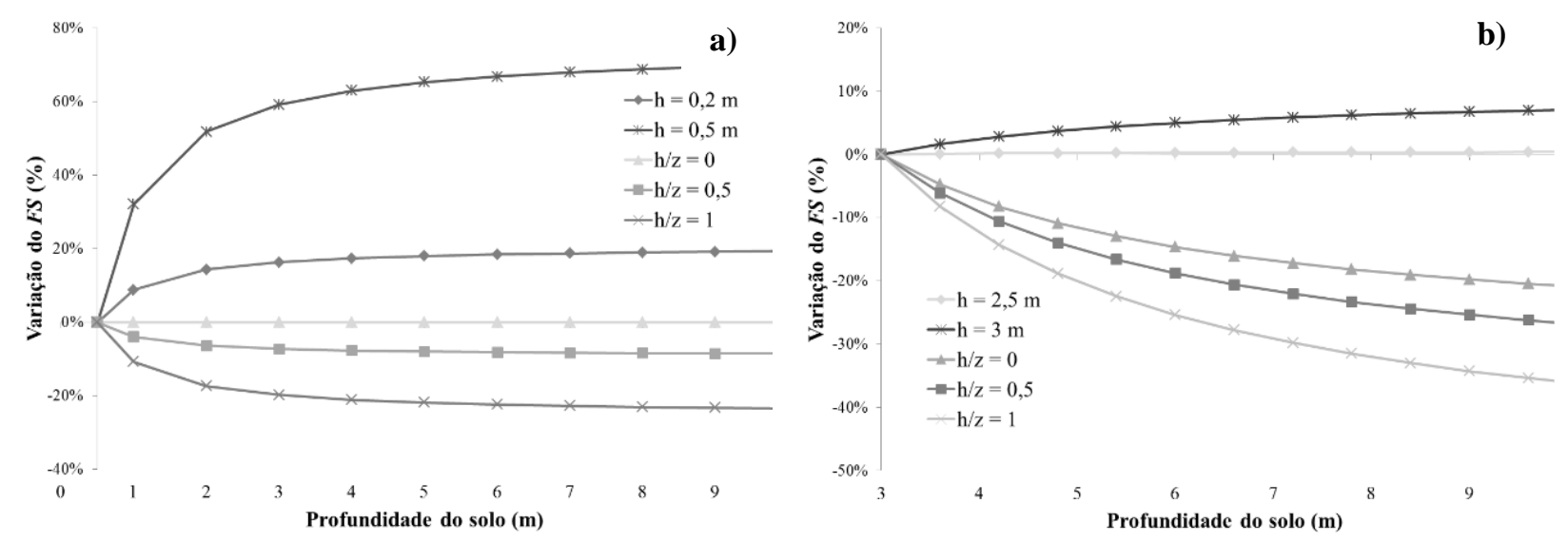

Figura 5. Variação do FS em função de $z$. a) Condição de ausência de forças coesivas e $V_{e . .}$ b) Condição de existência de forças coesivas e $V_{e}$

Tratando-se dos parâmetros relacionados à presença da vegetação nas encostas constata-se a grande influência de $c_{r}$ no valor do FS. Na profundidade de $1 \mathrm{~m}$, a supressão de $c_{r}$ reduz em $40 \%$ o $F S$. Da mesma maneira, duplicando o valor de $c_{r}$ há um aumento de $40 \%$ no valor de $F S$. A influência deste parâmetro diminui com o aumento de $z$ (Figura 6) sendo que, considerando o valor adotado como limite de alcance para a zona de raízes, a partir de $3 \mathrm{~m}$ de profundidade torna-se irrelevante.

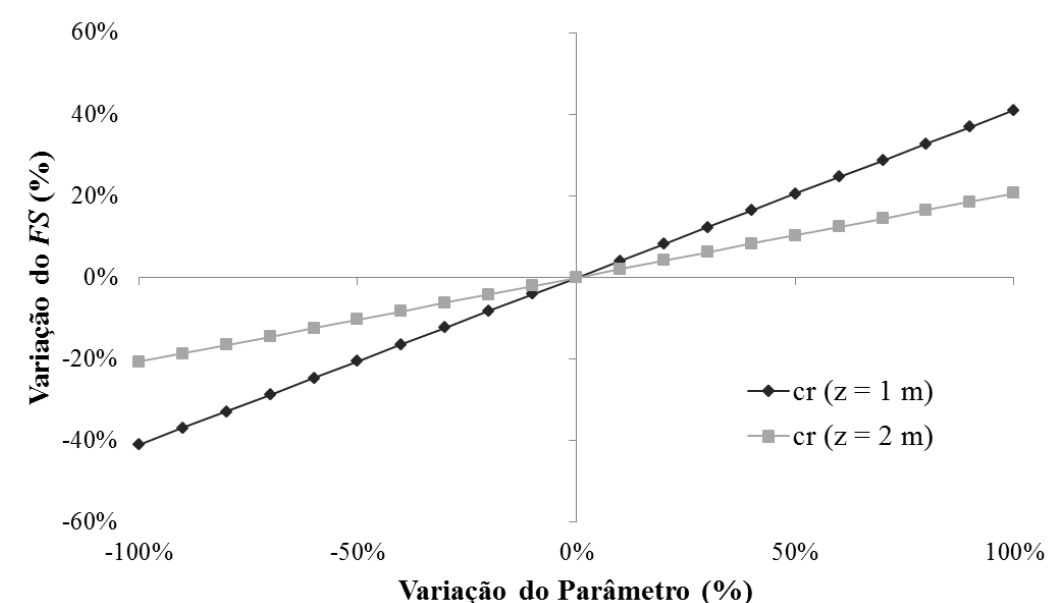

Figura 6. Análise de sensibilidade de FS à variação de $c_{r}$ para diferentes profundidades de solo.

A $S_{w}$ exerce influência significativa sobre $F S$ em solos rasos. A $1 \mathrm{~m}$ de profundidade a variação deste parâmetro dentro dos limites estabelecidos pode gerar variações do FS na ordem de $20 \%$. Entretanto, 
profundidades maiores atenuam a influência deste parâmetro e a partir de 3-4 $\mathrm{m}$ de profundidade este se torna irrelevante. Em profundidades mais elevadas, $S_{w}$ passa a auxiliar na estabilidade das encostas, efeito similar ao ocorrido com $\rho_{s}$ (Figura 7).

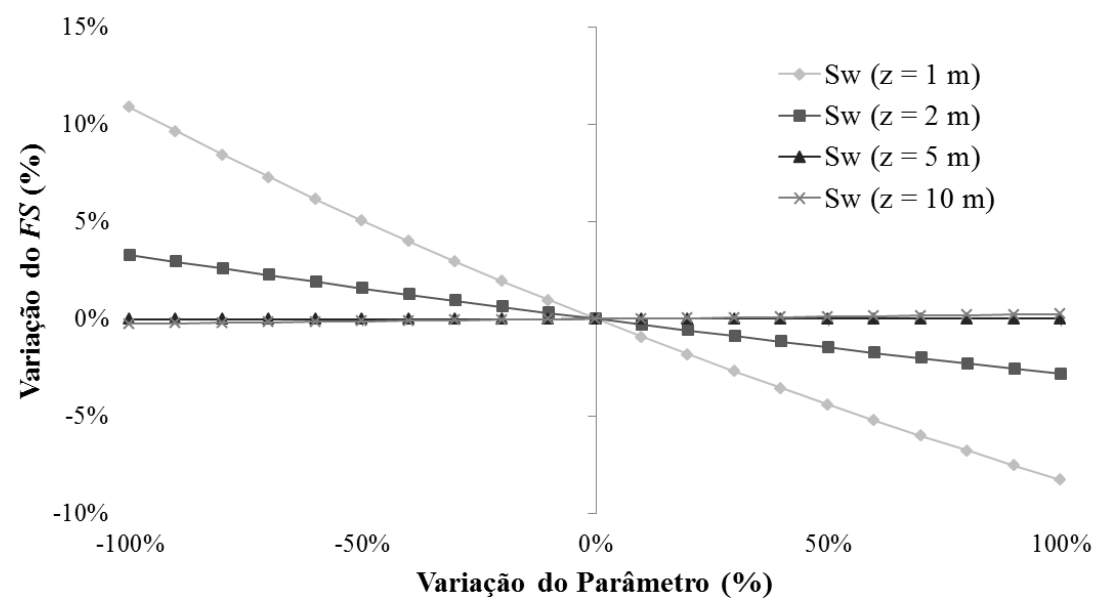

Figura 7. Análise de sensibilidade de $F S$ à variação de $S_{w}$ para diferentes profundidades de solo.

A $V_{e}$ exerce influência que vai de moderada a baixa sobre o $F S$. Esta influência também é atenuada com o aumento de $z$. Embora a Figura 8 mostre que a $1 \mathrm{~m}$ de profundidade este parâmetro possa alterar em aproximadamente $10 \%$ o FS, para que esta influência ocorra efetivamente, é necessário que o vento esteja soprando encosta abaixo e a uma velocidade considerável. A não ocorrência de alguma destas circunstâncias acarreta a cessação do efeito da força do vento na estabilidade da encosta.

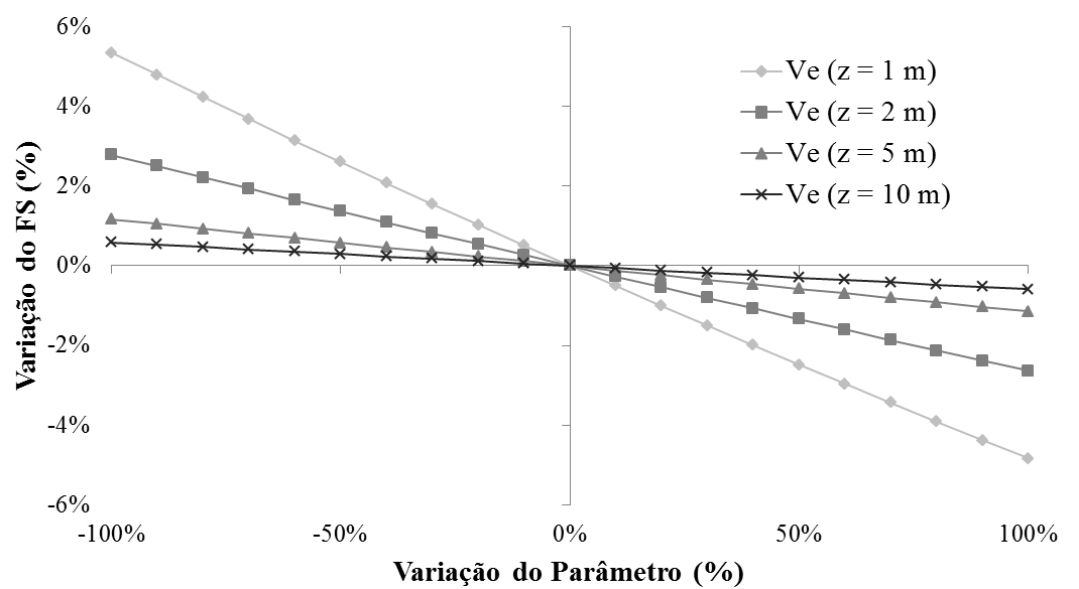

Figura 8. Análise de sensibilidade de $F S$ à variação de $V_{e}$ para diferentes profundidades de solo.

Utilizando a formulação proposta neste artigo para o $F S$, é possível realizar uma avaliação da evolução do $F S$ ao longo do tempo devido aos processos de corte e replantio de árvores e de aumento da espessura do solo. Sidle (1991) estabeleceu uma relação exponencial para a taxa de decaimento de $c_{r}$ a partir do corte da vegetação:

$$
D=e^{-k t^{n}}
$$

onde $D$ é um parâmetro adimensional para decaimento de $c_{r}$, $t$ é o tempo em anos a partir do corte, e $k$ e $n$ são constantes empíricas. Estas constantes dependem do clima local. O equacionamento para um parâmetro de crescimento de $c_{r}$ devido ao replantio das árvores também foi estabelecido por Sidle (1991):

$$
R=\left(f+g_{r} e^{-k t}\right)^{-1}+h_{r}
$$

onde $R$ é um parâmetro adimensional para crescimento de $c_{r}$ e $k, f, g_{r}$ e $h_{r}$ são constantes empíricas que definem a curva sigmóide de crescimento. A proporção de $c_{r}$ atuante em dado momento é dada pela soma dos dois parâmetros $(D$ e $R)$. 
O peso da vegetação sobre a encosta é reduzido a zero no momento do corte. O aumento do peso da vegetação devido ao replantio também pode ser descrito pela Eq. (14).

Os escorregamentos ocorrem naturalmente em locais com características geomorfológicas bem definidas, as concavidades topográficas (hollows). A partir do momento de ocorrência de um escorregamento, o processo de aumento da espessura do solo (soil infilling) inicia-se. Sidle e Ochiai (2006) relatam que este processo é muito complexo e depende de inúmeras variáveis geomorfológicas e hidrológicas. Além disso, propõem um equacionamento para descrevê-lo:

$$
z(t)=z_{o}+i_{z} e^{j / t}
$$

onde $z(t)$ é a profundidade do solo em metros no tempo $t ; z_{0}$ é a profundidade do solo no início do processo; $i_{z}=z_{\infty}$ - $z_{0}$; onde $z_{\infty}$ é o limite superior de acréscimo de solo; $t$ é o tempo em anos; e $j=-2 t_{i}$; onde $\left(t_{i}, z_{i}\right)$ é o ponto de inflexão da curva de recobrimento do solo.

Utilizando as Eq. (14) e Eq. (15), foi estimado um padrão de variação do $F S$ ao longo do tempo. Considerando que a superfície de ruptura do escorregamento formou-se abaixo da zona de raízes, a $c_{r}$ logo após a ocorrência de um escorregamento torna-se nula. Adotando uma taxa de crescimento das árvores e aumento da espessura do solo, a Figura 9a descreve o comportamento de $F S$ ao longo do tempo.

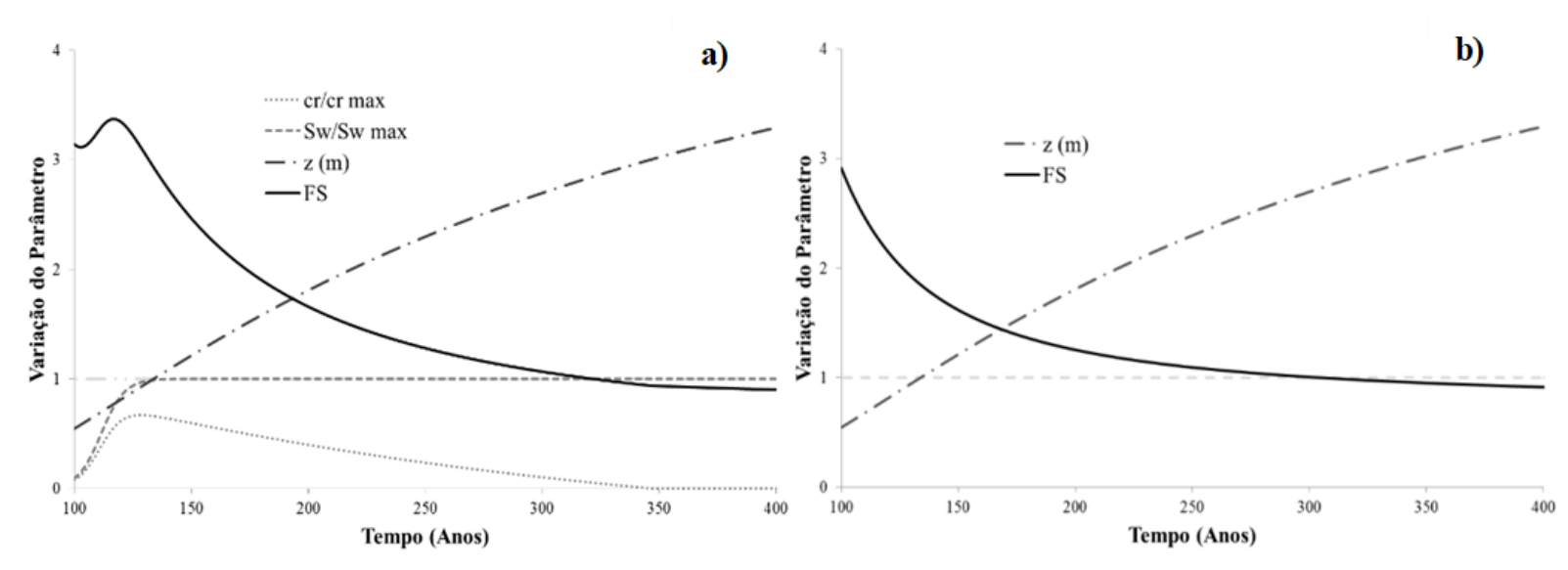

Figura 9. Evolução hipotética do FS após a ocorrência de um escorregamento a) com vegetação e b) sem vegetação.

Para ajuste da curva de aumento da espessura do solo foram utilizados os seguintes parâmetros: $z_{0}=0, i_{z}=6 \mathrm{e}$ $j=-2,4.10^{3}$. Para ajuste da curva $R$ de crescimento de $c_{r}$ e $S_{w}$, foram utilizados os seguintes parâmetros: $f=1, g_{r}=10$, $k=0,2$ e $h_{r}=0$. Também foi utilizado o pressuposto de redução da $R A R$ com o aumento de $z$. A $c_{r} \max$ e $S_{w}$ max adotadas foram de $20 \mathrm{kPa}$ e 2,6 kPa, respectivamente. Foi admitido que o processo de crescimento de vegetação sobre o solo iniciou-se após um período inicial de acumulação de solo (aproximadamente 100 anos). Este período refere-se ao tempo necessário para formação de uma camada suporte mínima para estabelecimento da vegetação nativa. Foi adotada uma declividade de $40^{\circ}$ para a encosta simulada. Os valores adotados para os demais parâmetros foram os valores centrais também utilizados durante a análise de sensibilidade.

A Figura 9a demonstra que após a ocorrência do escorregamento e estabelecimento de uma camada mínima de solo, o crescimento de nova vegetação gera uma elevação nos valores de $F S$. O pico do $F S$ se dá juntamente com o pico dos valores de $c_{r}$. A partir do momento em que a $c_{r}$ passa a decrescer (aproximadamente 30 anos), devido ao aumento da espessura do solo e redução da $R A R$ em uma possível superfície de ruptura, há também o decrescimento do $F S$. A redução nos valores de $F S$ deve-se à diminuição da resistência originada pela $c_{r}$ e também pelo aumento de $z$, que nessas condições diminui a estabilidade da encosta. Hipoteticamente, observa-se que após aproximadamente 320 anos, o FS torna-se menor que 1. Isto sinaliza a ocorrência de um novo escorregamento no mesmo local. Este evento se dá em uma camada de solo de aproximadamente 2,85 m. Assim, pode-se dizer que os escorregamentos neste local ocorrem com uma frequência de 1 a cada 320 anos com uma magnitude que abrange uma camada de solo de 2,85 $\mathrm{m}$ de profundidade.

A Figura 9b demonstra o comportamento de $F S$ ao longo do tempo considerando o não estabelecimento de nova vegetação sobre a camada de solo. Sem a ocorrência da vegetação há uma modificação na magnitude e na 
frequência do fenômeno. O FS torna-se menor que 1 após aproximadamente 300 anos. Isto ocorreu a uma profundidade de solo de aproximadamente $2,72 \mathrm{~m}$. Houve aumento da frequência e redução da magnitude do fenômeno. Em encostas menos íngremes, onde as condições de declividade possibilitam o estabelecimento de uma superfície de ruptura com camada de solo maior que $3 \mathrm{~m}$ de profundidade, a presença ou ausência da $c_{r}$ não gera modificações na magnitude e na frequência do fenômeno. Entretanto, a presença de $S_{w}$ é capaz de modificar, ainda que levemente, a magnitude e a frequência dos escorregamentos. Visto que em solos de profundidade elevada o aumento de $S_{w}$ melhora as condições de estabilidade, há uma redução na frequência e um aumento da magnitude do evento. Reciprocamente, em encostas mais declivosas, onde as superfícies de ruptura do solo formam-se em profundidades mais rasas, o efeito de $c_{r}$ na redução da frequência dos eventos é mais acentuado. De qualquer maneira se percebe que embora a vegetação nativa, em grande parte dos casos, desempenhe importante papel na redução da frequência dos eventos de escorregamentos, o aumento da magnitude destes eventos é uma consequência eminente. Assim, a razão da magnitude pela frequência permanece inalterada.

\subsection{Aplicação do SHALSTAB modificado}

O algoritmo modificado do modelo SHALSTAB foi aplicado à bacia do rio Cunha com o propósito de avaliar a sensibilidade do modelo à variação dos parâmetros relacionados à presença de vegetação e demais parâmetros. A aplicação do modelo depende de características topográficas, geotécnicas e hidrológicas. A $\theta$ da encosta e a $a / b$ em cada ponto foram extraídas diretamente do MDT da bacia (Figura 10).
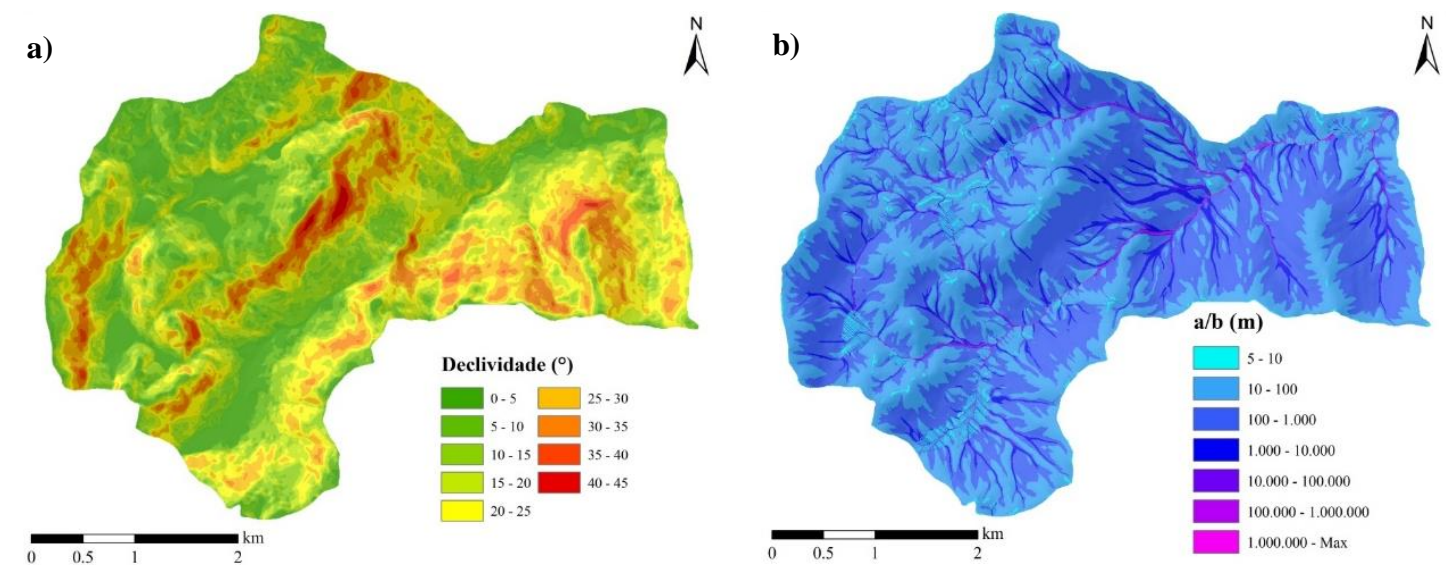

Figura 10. a) Mapa de $\theta$ e b) mapa de $a / b$ da bacia do rio Cunha.

A bacia do rio Cunha apresenta a maior parte de sua área (aproximadamente $45 \%$ ) em relevo ondulado, com declividades variando entre $5^{\circ}$ e $12^{\circ}$ (EMBRAPA, 2009), onde não é comum a ocorrência de processos de escorregamento. Entretanto, existem diversos locais da bacia que apresentam encostas montanhosas $\left(\theta\right.$ entre $24^{\circ} \mathrm{e}$ $\left.37^{\circ}\right)$ e escarpadas $\left(\theta>37^{\circ}\right)$, onde os escorregamentos são recorrentes. Além disso, há aproximadamente $21 \%$ da área em relevo forte ondulado $\left(\theta\right.$ entre $12^{\circ}$ e $\left.24^{\circ}\right)$, onde os processos de escorregamento são altamente dependentes das características pedológicas e hidrológicas.

O mapa da área de contribuição demonstra similaridade com a rede de drenagem da bacia, pois captura o efeito da topografia no fluxo da água. Montgomery e Dietrich (1994) destacaram que há grande incidência de escorregamentos nas concavidades topográficas (hollows), que são locais onde há convergência do fluxo e transporte de partículas de solo a partir das cabeceiras. Na ausência de fluxo permanente de água por canais para remoção do solo acumulado, a espessura do solo cresce até que se torne instável. Além disso, assumindo convergência do fluxo subsuperficial similar ao superficial, durante um evento chuvoso, as concavidades topográficas (hollows) apresentam maiores níveis de saturação do solo, gerando maior propensão para escorregamentos. Para os valores de $z$ de 1 e $2 \mathrm{~m}$, assumindo a combinação de valores estabelecida ao longo de todo o terreno, não foi constatada a incidência de áreas instáveis dentro da bacia, impedindo assim a verificação da sensibilidade do modelo à variação dos parâmetros. Desta maneira, optou-se por uma redução do valor central 
dos parâmetros de resistência da encosta de modo que a bacia inicialmente apresentasse uma parcela considerável de área instável. Os parâmetros de entrada utilizados para cada profundidade estão na Tabela 3.

Tabela 3. Valores centrais dos parâmetros utilizados na modelagem.

\begin{tabular}{|c|c|c|c|c|c|}
\hline \multirow{2}{*}{ Parâmetro } & \multicolumn{4}{|c|}{ Valor central da profundidade } & \multirow{2}{*}{$\begin{array}{c}\text { Variação } \\
\pm 100 \%\end{array}$} \\
\hline & $1 \mathrm{~m}$ & $2 \mathrm{~m}$ & $5 \mathrm{~m}$ & $10 \mathrm{~m}$ & \\
\hline$S_{w}(\mathrm{kPa})$ & \multicolumn{4}{|c|}{2,6} & $\pm 100 \%$ \\
\hline$c_{r}(\mathrm{kPa})$ & 4 & 8 & \multicolumn{2}{|c|}{-} & $\pm 100 \%$ \\
\hline$c_{s}(\mathrm{kPa})$ & 2,38 & 4,76 & \multicolumn{2}{|c|}{11,90} & $\pm 100 \%$ \\
\hline$\phi\left({ }^{\circ}\right)$ & 20 & 25 & \multicolumn{2}{|c|}{31.2} & $\pm 70 \%$ \\
\hline$\rho_{s}\left(\mathrm{~kg} \mathrm{~m}^{-3}\right)$ & \multicolumn{4}{|c|}{1750} & $\pm 20 \%$ \\
\hline$T\left(\mathrm{~m}^{2} \mathrm{dia}^{-1}\right)$ & 4.5 & 9 & 22.5 & 45 & $-90 ;+200 \%$ \\
\hline$q\left(\mathrm{~mm} \mathrm{dia}^{-1}\right)$ & 3,58 & 7,15 & 17,9 & 35,8 & $\pm 50 \%$ \\
\hline
\end{tabular}

A não ocorrência de escorregamentos em profundidades rasas na bacia do rio Cunha em novembro de 2008, mesmo em condições climatológicas tão adversas, sugere que a susceptibilidade da bacia a escorregamentos nas camadas superficiais do solo seja baixa. A precipitação acumulada na região em pouco mais de três meses foi de $1200 \mathrm{~mm}$ (2/3 da média anual do município) com intensidades superando $120 \mathrm{~mm}$ dia-1 $^{-1}$. Em novembro de 2008, os escorregamentos ocorridos na bacia iniciaram-se em profundidades de aproximadamente $10 \mathrm{~m}$. Deste modo, considerando que grande parte da bacia apresenta cobertura vegetal de floresta densa, pode ser inferido que, em profundidades rasas, os parâmetros de resistência da vegetação combinados com os parâmetros de resistência do solo são capazes de estabilizar a encosta. Assim, o fato de o modelo não detectar instabilidades em profundidades rasas não difere do que foi observado na bacia. Em profundidades maiores, há o aumento do peso do solo e redução de $c_{r}$, aumentando assim a suscetibilidade a escorregamentos. Ressalta-se que, embora a instabilidade tenha sido induzida pela redução dos parâmetros de resistência nas profundidades de 1 e $2 \mathrm{~m}$, as áreas instáveis da bacia sempre coincidiram em sua maioria com as áreas instáveis detectadas pelo modelo para as profundidades de 5 e $10 \mathrm{~m}$ utilizando os valores inalterados dos parâmetros de entrada e com as cicatrizes de escorregamentos. A Figura 11 mostra os mapas de estabilidade gerados com os valores centrais dos parâmetros.
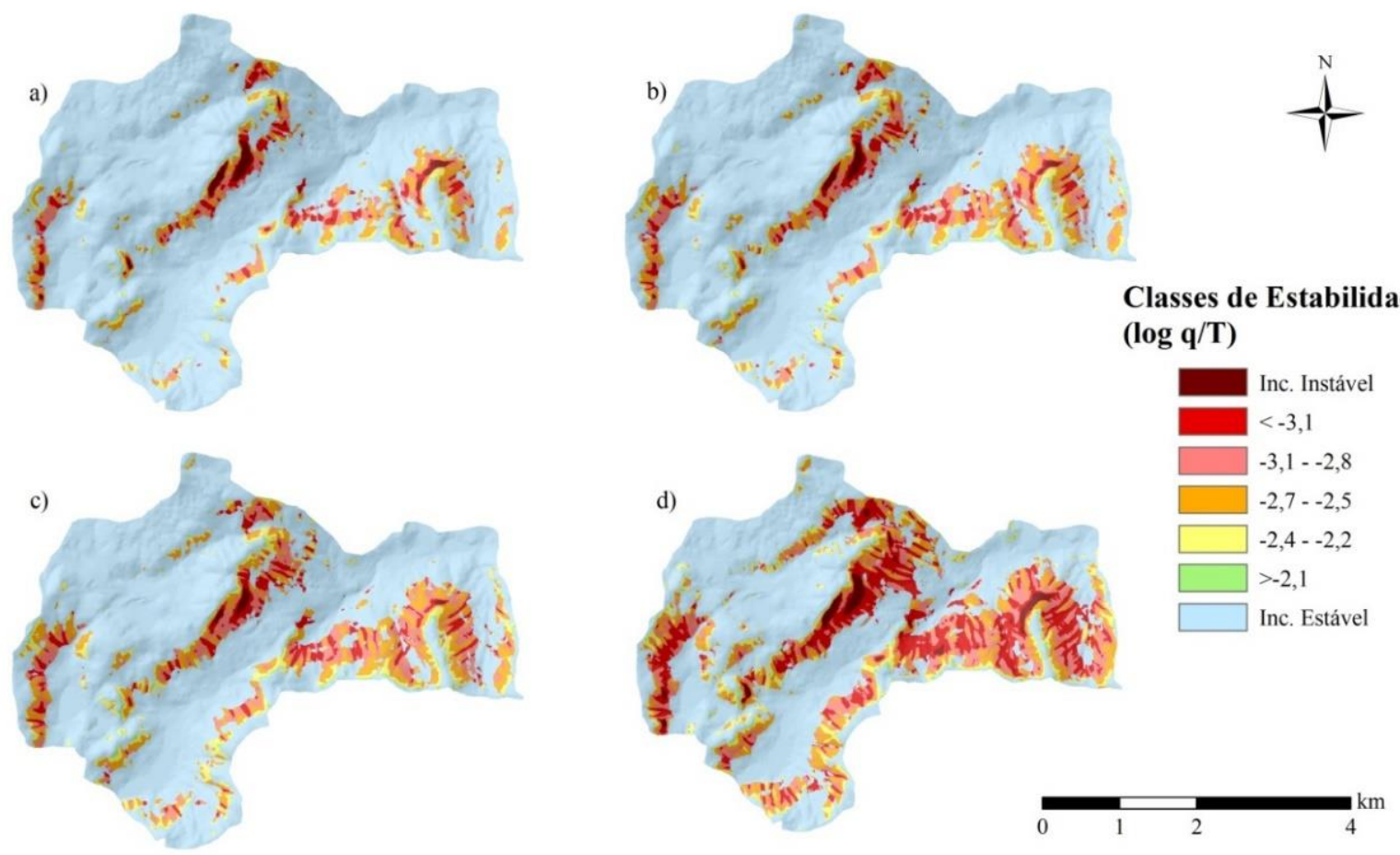

Figura 11. Mapas de estabilidade da bacia do rio Cunha para diferentes cenários. a) $z=1 \mathrm{~m}, \mathrm{~b}) z=2 \mathrm{~m}, \mathrm{c}) z=5 \mathrm{~m}$, e d) $z=10 \mathrm{~m}$. 
A Tabela 4 mostra a porcentagem de área em cada classe de estabilidade quando utilizados na modelagem os valores centrais dos parâmetros. Assim, ao avaliar o efeito da variação dos parâmetros na quantidade de área instável dentro da bacia, 3,38; 3,88; 4,34; e 13,45\% são as máximas reduções concebíveis para as profundidades de $1,2,5$ e $10 \mathrm{~m}$, respectivamente.

Tabela 4. Porcentagem de área por classe de estabilidade.

\begin{tabular}{c|c|c|c|c}
\hline \multirow{2}{*}{ Classe } & \multicolumn{4}{|c}{ Área (\%) } \\
\cline { 2 - 5 } & $\boldsymbol{z = \mathbf { 1 } \mathbf { ~ }}$ & $\boldsymbol{z} \mathbf{2} \mathbf{~ \mathbf { ~ }}$ & $\boldsymbol{z} \mathbf{5} \mathbf{~ \mathbf { ~ }}$ & $\boldsymbol{z} \mathbf{\mathbf { 1 0 }} \mathbf{~ \mathbf { y }}$ \\
\hline $\begin{array}{c}\text { Incondicionalmente. } \\
\text { Instável }\end{array}$ & 0,81 & 0,51 & 0,26 & 1,37 \\
\hline $\log q / T \leq-3,1$ & 2,57 & 3,37 & 4,08 & 12,08 \\
\hline$-3,1<\log q / T \leq-2,8$ & 4,24 & 5,77 & 7,21 & 11,18 \\
\hline$-2,8<\log q / T \leq-2,5$ & 5,53 & 7,49 & 9,30 & 10,49 \\
\hline$-2,5<\log q / T \leq-2,2$ & 2,55 & 3,50 & 4,51 & 5,37 \\
\hline $\log q / T>-2,2$ & 0,42 & 0,62 & 0,78 & 0,86 \\
\hline Incondicionalmente & 83,89 & 78,73 & 73,87 & 58,66 \\
\hline Estável & & & & \\
\hline
\end{tabular}

A variação dos parâmetros de entrada relacionados aos efeitos mecânicos da vegetação foi realizada de modo a contemplar a gama de possibilidades existentes de valores. Ao aumentar ao máximo os parâmetros $c_{r}$ e $S_{w}$, supôs-se que existe grande densidade de vegetação atuando nos processos de estabilidade da encosta. Ao suprimir estes parâmetros, supôs-se a ausência da mesma. A variação dos parâmetros hidrológicos do modelo foi realizada na tentativa de simular o efeito da vegetação no ciclo hidrológico da encosta. Considerando que a vegetação pode ampliar significativamente a condutividade do solo, os valores de taxa de recarga uniforme e transmissividade foram aumentados. Considerando os fenômenos de interceptação e evapotranspiração, a taxa de recarga uniforme foi reduzida. A Figura 12 mostra a variação percentual da área instável na bacia devido à variação dos parâmetros de entrada do modelo. A linha tracejada em cada figura representa a máxima redução possível da área instável. 

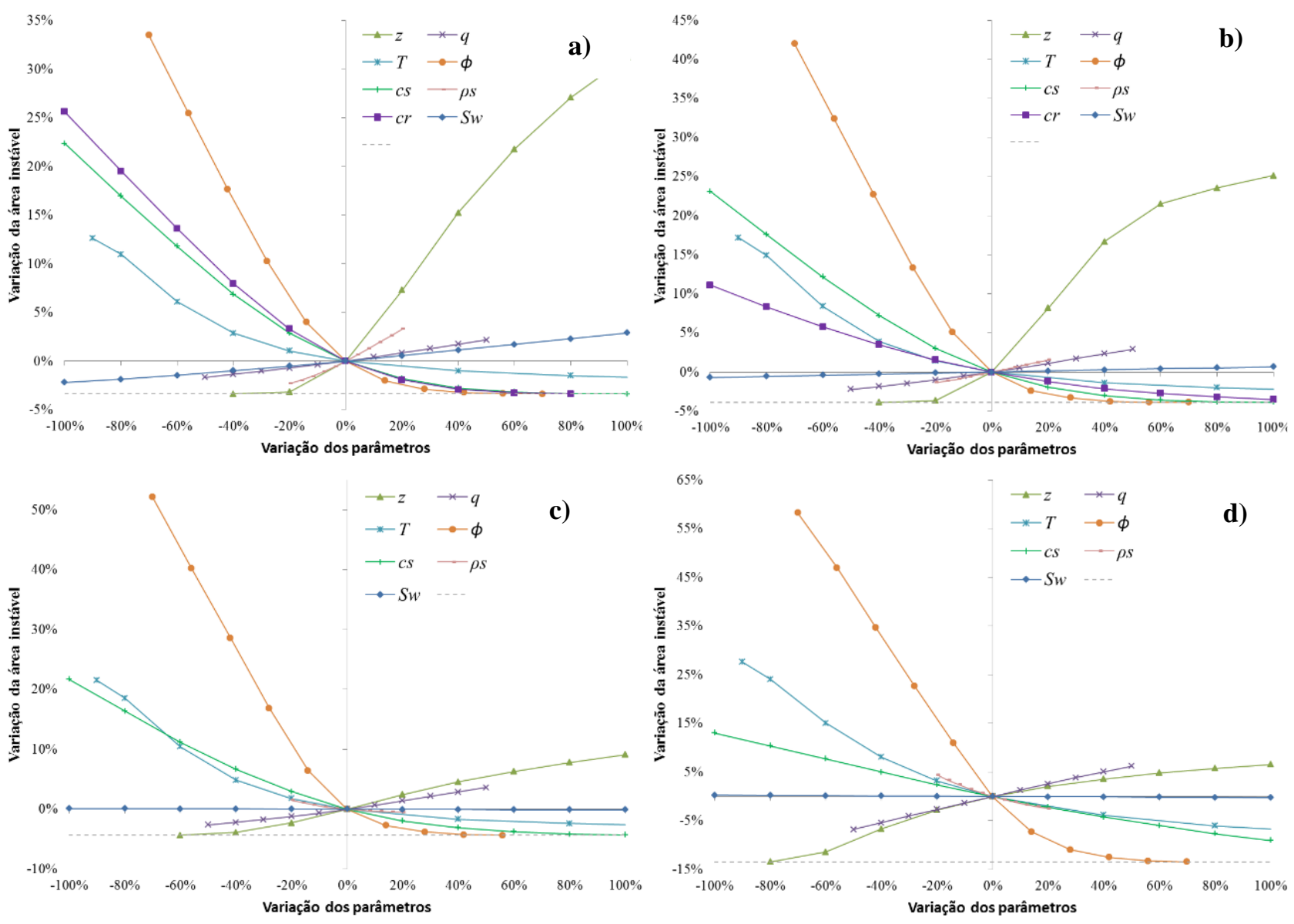

Figura 12. Variação da área instável em função da variação de cada parâmetro a) $\mathrm{z}=1 \mathrm{~m}, \mathrm{~b}) \mathrm{z}=2 \mathrm{~m}, \mathrm{c}) \mathrm{z}=5 \mathrm{~m}, \mathrm{e}$ d) $\mathrm{z}=10 \mathrm{~m}$.

Em primeiro lugar, observa-se a contribuição sempre benéfica do aumento dos parâmetros de resistência do solo $c_{s}$ e $\phi$. Bem como o constatado pela análise de sensibilidade do $F S$, a contribuição de $c_{s}$ para estabilização das encostas é mais relevante em profundidades mais rasas. Ao analisar camadas de solo mais espessas percebe-se que $\phi$, embora seja o parâmetro de resistência do solo que mais contribua para a estabilidade da encosta em qualquer profundidade, aumenta a efetividade de sua contribuição com o aumento da espessura do solo. O crescimento de $\rho_{\mathrm{s}}$ aumenta a área instável da bacia nas profundidades de 1 e $2 \mathrm{~m}$. Nas profundidades de 5 e $10 \mathrm{~m}$, o crescimento de $\rho_{s}$ gera redução das áreas instáveis.

Em relação aos parâmetros inseridos no modelo, houve grande sensibilidade à $c_{r}$ em profundidades rasas. A $1 \mathrm{~m}$ de profundidade, a ausência de $c_{r}$ aumentou em aproximadamente $25 \%$ a área instável da bacia. Ainda nesta profundidade, ao aumentar em $80 \%$ o valor central de $c_{r}$ não são mais constatadas áreas instáveis na bacia. A $2 \mathrm{~m}$ de profundidade, a sensibilidade do modelo à $c_{r}$ se reduz, tanto pela taxa de decrescimento da $R A R$ adotada quanto pelo aumento do peso do solo que faz com que a efetividade deste parâmetro na estabilização da encosta diminua. Para profundidades maiores que $3 \mathrm{~m}$ a $c_{r}$ não foi computada.

A sensibilidade do modelo ao parâmetro $S_{w}$ foi moderada em solos pouco espessos e fraca em solos profundos. Foi na profundidade de $1 \mathrm{~m}$ que o modelo apresentou maior sensibilidade a este parâmetro, variando em cerca de $5 \%$ sua área instável devido a sua variação. Semelhante ao que ocorre com $\rho_{s,}$ em solos profundos, o aumento de $S_{w}$ passa a auxiliar levemente na estabilidade da encosta, levando a redução das áreas instáveis. Em relação à sensibilidade do modelo à variação de $z$, é notável que a estabilidade das encostas é muito mais afetada em solos rasos do que em profundos. Ao se reduzir $z$ durante a análise de sensibilidade, há uma zona de transição a partir da qual não são mais verificadas áreas instáveis. Esta condição se estabelece pela atuação de $c_{r}$ nas profundidades mais rasas do solo. Dietrich et al. (1982) relataram que nas concavidades topográficas (hollows) há um crescimento contínuo da camada de solo e consequentemente a efetividade de $c_{r}$ gradativamente diminui. 
Desta maneira, em locais onde a vegetação atribui grande aporte de coesão a encosta, os escorregamentos geralmente formam-se em camadas do solo abaixo da zona de raízes.

O parâmetro $q$ apresentou influência moderada, ocorrendo o aumento da área instável da bacia com o crescimento deste parâmetro. Considerando que a vegetação, através da interceptação e transpiração, pode reduzir o volume da precipitação que chega ao solo em até $50 \%$, isto geraria uma redução de aproximadamente $7 \%$ da área instável da bacia na profundidade de $10 \mathrm{~m}$. Na profundidade de $1 \mathrm{~m}$ esta influência cai para aproximadamente $2 \%$. Da mesma maneira, considerando que a vegetação pode aumentar o valor de $q$ pelo favorecimento da infiltração da água no solo, o aumento da área instável é de aproximadamente 7 e $2 \%$ para as profundidades de 10 e $1 \mathrm{~m}$, respectivamente. Por alterar as características de condutividade hidráulica do solo, a vegetação pode aumentar o valor de $T$. Dentre os parâmetros hidrológicos $(q$ e $T)$, houve maior sensibilidade do modelo à variação de $T$. Na profundidade de $10 \mathrm{~m}$, considerando que a condutividade hidráulica pode mudar consideravelmente com a vegetação, obteve-se uma redução de mais de $30 \%$ na porcentagem de área instável dentro da bacia com o aumento de T. Para profundidades menores, o efeito diminui. De qualquer maneira, os parâmetros hidrológicos $q$ e $T$ tem maior influência sobre os resultados do modelo em solos com maior espessura.

A análise da influência da vegetação na estabilidade de encostas, em relação aos parâmetros hidrológicos, realizada com o modelo hidrológico de estado uniforme traz uma abordagem muito simplista dos processos envolvidos. Em relação à infiltração, Iverson (2000) introduziu o conceito de que existem diferentes escalas temporais para os processos de saturação e escorregamento do solo das encostas. Estas escalas referem-se aos processos de infiltração da água no sentido vertical e posteriormente sua percolação lateral pela encosta. Para que seja realizada uma análise detalhada da contribuição da vegetação no desencadeamento de escorregamentos por ação dos processos hidrológicos, é necessário estes sejam corretamente contemplados pelos modelos e que as possíveis influências sejam mais bem especificadas.

\section{Conclusões}

A vegetação pode exercer influência relevante sobre a estabilidade das encostas modificando sua suscetibilidade à ocorrência de escorregamentos. O presente trabalho teve como principal objetivo investigar a influência da vegetação de floresta nativa secundária sobre a estabilidade das encostas através da reformulação e análise de sensibilidade do FS e do modelo SHALSTAB.

A análise de sensibilidade do equacionamento proposto para o FS demonstrou que $c_{r}$ pode influenciar fortemente, de maneira positiva, no resultado das análises de estabilidade. A influência deste parâmetro decai com o aumento de $z$. Por isso, ao considerar a atuação das raízes no reforço da encosta, observar a profundidade do solo na qual poderá se formar a superfície de ruptura é de extrema importância. A sensibilidade do FS ao parâmetro $S_{w}$ foi moderada em condições de solos pouco espessos, onde influencia negativamente o FS. O aumento da profundidade reduz a sensibilidade do FS a este parâmetro e, a partir de certa profundidade, $S_{w}$ passa a contribuir para a estabilidade da encosta. O FS mostrou-se pouco sensível ao parâmetro $V_{e}$, além disso a presença deste efeito está vinculada a uma série de condições como velocidade e direção do vento, e características da cobertura vegetal. Observou-se um padrão indefinido para a $\rho_{s}$, dependente da profundidade do solo.

A equação de FS se mostrou fortemente sensível a declividade, sendo de grande relevância a correta estimativa da declividade para o cálculo de FS. Também deve ser analisada, caso a caso, a faixa de valores para qual FS é válida, visto que o valor de FS varia até um ponto de mínimo da função, em que valores maiores apresentam pouca influência no cálculo de FS. Assim, a validade da equação de FS deve ser avaliada com cuidado considerando que áreas declivosas são menos estáveis.

Os parâmetros $c_{r}$ e $S_{w}$ foram inseridos no modelo SHALSTAB devido a sua relevância na estabilidade das encostas. Ao realizar a análise de sensibilidade do modelo modificado à variação dos parâmetros de entrada verificou-se comportamento similar àquele demonstrado pelo FS. Deste modo constata-se que a formulação proposta para o modelo é coerente com o FS e que o acoplamento do modelo hidrológico não alterou o comportamento do equacionamento. Devido à influência dos parâmetros mecânicos relacionados à presença de vegetação, é aconselhável que tais parâmetros sejam considerados na modelagem. Os escorregamentos que ocorreram na bacia do rio Cunha em novembro de 2008 formaram-se em camadas profundas do solo. Ademais, não foi observada incidência de escorregamentos rasos na bacia. Estas circunstâncias provavelmente resultaram 
da ação das raízes na coesão em solos rasos. A contribuição de $S_{w}$, mesmo sendo mais amena que a de $c$ r, pode ser crucial na análise de escorregamentos, principalmente em locais onde os índices de estabilidade aproximam-se do limiar. Desta maneira, a formulação modificada do SHALSTAB proposta pelo presente trabalho pode ser utilizada na análise de estabilidade de encostas com a presença de vegetação.

A influência da vegetação na variação dos parâmetros hidrológicos e consequentemente na análise de estabilidade demonstrou ser significativa. Entretanto, os processos hidrológicos que ocorrem nas encostas e que sofrem interferência da vegetação são muito complexos e dificilmente podem ser analisados por um modelo hidrológico simplista como o modelo de estado uniforme. A interceptação altera a intensidade e a distribuição da chuva que chega ao solo. A presença de uma camada de folhas e raízes sobre o solo modifica as taxas de infiltração. A absorção de água do solo pelas raízes e posterior transpiração modificam as condições de umidade antecedente. Todos estes fenômenos apresentam variabilidade ao longo do tempo e ocorrem em escalas temporais distintas. Assim, a utilização de um modelo dinâmico para avaliação das condições hidrológicas da encosta poderá gerar resultados mais precisos.

Contribuições dos Autores: Gean Paulo Michel: Concepção, metodologia, software, validação, análise formal, preparação de dados; Masato Kobiyama: Recursos, revisão, supervisão, aquisição de financiamento; Roberto Fabris Goerl: preparação de dados, pesquisa, revisão; Franciele Zanandrea: escrita do artigo, análise formal, metodologia; Leonardo Rodolfo Paul: análise formal, software, escrita do artigo; Heron Schwarz: metodologia e escrita do artigo; Gabriel Lopes Cardozo: preparação de dados e escrita do artigo.

Financiamento: Esta pesquisa foi financiada pelo Conselho Nacional de Desenvolvimento Científico e Tecnológico (CNPq).

Conflito de Interesse: Os autores declaram não haver conflito de interesse. Os financiadores não tiveram interferência no desenvolvimento do estudo; na coleta, análise ou interpretação dos dados; na redação do manuscrito, ou na decisão de publicar os resultados.

Nota Explicativa: Este artigo é parte da dissertação de mestrado do primeiro autor, Gean Paulo Michel (1) desenvolvida sob orientação de Masato Kobiyama (2) e defendida em março de 2013 no Programa de Pós-graduação em Engenharia Ambiental da Universidade Federal de Santa Catarina.

\section{Referências}

1. AVELAR A.S.; NETTO A.L.C.; LACERDA W.A.; BECKER L.B.; MENDONÇA M.B. Mechanisms of the Recent Catastrophic Landslides in the Mountainous Range of Rio de Janeiro, Brazil. In: MARGOTTINI C.; CANUTI P.; SASSA K. (org.) Landslide Science and Practice. Heidelberg: Editora Springer, 2013. p. 265-270. DOI: 10.1007/978-3-642-31337-0_34.

2. BAETS, S.; REUBENS, B.; WEMANS, K.; DE BAERDEMAEKER, J.; MUYS, B. Root tensile strength and root distribution of typical Mediterranean plant species and their contribution to soil shear strength. Plant and Soil, v. 305, n. 1-2, p. 207-226, 2008. DOI: 10.1007/s11104-008-9553-0.

3. BEVEN, K.J.; KIRKBY, M.J. A physically based, variable contributing area model of basin hydrology / Un modèle à base physique de zone d'appel variable de l'hydrologie du bassin versant. Bulletin of the International Association of Scientific Hydrology, v. 24, n. 1, p. 43-69, 1979. DOI: 10.1080/02626667909491834.

4. BISCHETTI, G.; CHIARADIA, E. A.; EPIS, T.; MORLOTTI, E. Root cohesion of forest species in the Italian Alps. Plant and Soil, v. 324, n. 1-2, p. 71-89, 2009. DOI: 10.1007/s11104-009-9941-0.

5. BISHOP, A. W. The Use of the Slip Circle in the Stability Analysis of Slopes Géotechnique, London, v.5, n.1, p.7-17, 1955. DOI: 10.1680/geot.1955.5.1.7.

6. BISHOP, D. M.; M. E. STEVENS. Landslides on logged areas in southeast Alaska. Alaska: USDA Forest Service Research Paper NOR-1, Northern Forest Experiment Station, Juneau, 1964. 18p. ISBN 0265846439.

7. BORGA, M.; FONTANA, G. D.; GREGORETTI, C.; MARCHI, L. Assessment of shallow landsliding by using a physically based model of hillslope stability. Hydrological Processes, v. 16, n. 14, p. 2833-2851, 2002. DOI: 10.1002/hyp.1074. 
8. COElHO NETO, A. L.; SATO, A. M.; AVElAR, A. S.; VIANNA, L. G.; ARAÚJO, I. S.; FERREIRA, D. C.; LIMA, P. H.; SILVA, A. P. A.; SILVA, ROBERTA P. January 2011: The Extreme Landslide Disaster in Brazil. In: MARGOTTINI, C.; CANUTI, P.; SASSA, K. (org.) Landslide Science and Practice. Heidelberg: Editora Springer Berlin, 2013. p. 377-384. ISBN 978-3-642-31324-0.

9. COHEN, D.; SCHWARZ, M. Tree-root control of shallow landslides. Earth Surface Dynamics, v. 5, n. 3, p. $451,2017$. DOI: $10.5194 /$ esurf-5-451-2017.

10. COPPIN, N.J.; RICHARDS, I.G. Use of Vegetation in Civil Engineering. London: CIRIA, 1990. 237p. ISBN 0-408-03849-7. 11. CPRM - Serviço Geológico do Brasil. Mapa Geológico do estado de Santa Catarina, 2014. Disponível em: $<$ http://geobank.sa.cprm.gov.br/>.

12. DIETRICH, W. E. et al. Construction of sediment budgets for drainage basins. In: Sediment Budgets and Routing in Forested Drainage Basins: Proceedings of the Symposium; 31 May - 1 June 1982; Corvallis, Oregon. Gen. Tech. Rep. PNW-141. Portland, Oregon: Pacific Northwest Forest and Range Experiment Station, Forest Service, U.S. Department of Agriculture, p. $5-23,1982$.

13. DIETRICH, W. E.; MONTGOMERY, D. R. SHALSTAB: a digital terrain model for mapping shallow landslide potential. Publication NCASI (National Council of the Paper Industry for Air and Stream Improvement), 1998. 29p.

14. DORREN, L.; SCHWARZ, M. Quantifying the Stabilizing Effect of Forests on Shallow Landslide-Prone Slopes. In RENAUD, F.; SUDMEIER-RIEUX, K.; ESTELLA, M.; NEHREN, U. (org). Ecosystem-Based Disaster Risk Reduction And Adaptation In Practice. Cham: Editora Springer, 2016. p. 255-270. DOI:10.1007/978-3-319-43633-3_11.

15. EMBRAPA. Centro Nacional e Pesquisa em Solos. Sistema Brasileiro de Classificação de Solos. Rio de Janeiro: Embrapa-SPI, 2006, 306 p.

16. FRANK, B.; SEVEGNANI, L. Desastre de 2008 no Vale do Itajaí. Água, gente e política. Blumenau: Agência de Água do Vale do Itajaí, 2009. 24p.

17. GOERL, R.F.; KOBIYAMA, M.; CORREA, G.P; ROCHA, H.L.; GIGLIO, J.N. Desastre hidrológico resultante das chuvas intensas em Rio dos Cedros - SC. In: Simpósio Brasileiro de Recursos Hídricos, XVIII, 2009, Campo Grande Anais... Campo Grande: ABRH, CD-rom. 2009a, 19p.

18. GOERL, R.F.; KOBIYAMA, M.; LOURENÇO, L. L.; GRANDO, A. Características gerais dos escorregamentos ocorridos em novembro de 2008 nos municípios de Brusque, Rio dos Cedros e Timbó - SC. In: Simpósio Brasileiro de Geografia Física Aplicada, XIII, 2009, Minas Gerais. Anais... Viçosa: UFV. 2009, 16p.

19. GREENWAY, D. R. Vegetation and Slope Stability. In: ANDERSON, M. F.; RICHARDS, K. S. (Eds.) Slope Stability. Wiley and Sons, New York, 1987.

20. GUIMARÃES, R. F.; RAMOS, V. M.; REDIVO, A. L.; GOMES, R.; FERNANDES, R. F.; DE CARVALHO, O. A. Application of the SHALSTAB model for mapping susceptible landslide areas in mine zone (Quadrila/spl acute/tero Ferri/spl acute/fero in southeast Brazil). In: Geoscience and Remote Sensing Symposium, 2003. Toulouse. Anais... 2003 IEEE International: 2003, p.2444-2446.

21. HAMMOND, C.; HALL, D.; MILLER, S.; SWETIK, P. (1992) Level I Stability Analysis (LISA) Documentation for Version 2.0. Publication General Technical Report INT-285, USDA Forest Service Intermountain Research Station, 189p.

22. HSI, G.; NATH, J. H. Wind drag within simulated forest canopies. Journal of Applied Meteorology, v. 9, p. 592-602, 1970. DOI: 10.1175/1520-0450(1970)009<0592:WDWSFC>2.0.CO;2

23. HWANG, T.; BAND, L. E.; HALES, T. C.; MINIAT, C.; VOSE, J.; BOLSTAD, P. V.; MILES, B.; PRICE, K. Simulating vegetation controls on hurricane-induced shallow landslides with a distributed ecohydrological model. Journal of Geophysical Research: Biogeosciences, v. 120, n. 2, p. 361-378, 2015. DOI: 10.1002/2014JG002824. 
24. IBGE - Instituto Brasileiro de Geografia e Estatística. Gerência de Recursos Naturais e Estudos Ambientais - UE/SC. Projeto Gerenciamento Costeiro. Carta de reconhecimento de solos, geomorfologia e geologia da região de Blumenau. Folha SG.22-Z-b-IV (MI-2881). 2003. Escala: 1:250.000.

25. IVERSON, R. M. Landslide triggering by rain infiltration. Water Resources Research, v. 36, n. 7, p. 1897-1910, 2000. DOI: $10.1029 / 2000$ WR900090.

26. JI J.; KOKUTSE, N.; GENET. M.; FOURCAUD, T.; ZHANG, Z. Effect of spatial variation of tree root characteristics on slope stability. A case study on Black Locust (Robinia pseudoacacia) and Arborvitae (Platycladus orientalis) stands on the Loess Plateau, China. Catena, v. 92, p. 139-154, 2012. DOI: 10.1016/j.catena.2011.12.008.

27. KOBIYAMA, M.; GOERL, R. F.; CORREA, G. P.; MICHEL, G. P. Debris flow occurrences in Rio dos Cedros, Southern Brazil: meteorological and geomorphic aspects. In: WRACHIEN, D.; BREBBIA, C.A. (org.) Monitoring, Simulation, Prevention and Remediation of Dense Debris Flows III. Southampton: Editora WITpress, 2010, p.77-88. ISBN 978-1-84564-169-6.

28. KORUP, O. Large landslides and their effect on sediment flux in South Westland, New Zealand. Earth Surface Processes and Landforms, v. 30, n. 3, p. 305-323, 2005. DOI: 10.1002/esp.1143.

29. MARQUES, M. C. de O.; NETTO, A. L. C.; SATO, A. M. Influência de floresta secundária e gramínea na deflagração de deslizamentos translacionais rasos em Nova Friburgo, Rio de Janeiro. Revista Brasileira de Geomorfologia, v. 19, n. 4, p. 793-806, 2018. DOI: 10.20502/rbg.v19i4.1479.

30. MONTGOMERY, D. R.; DIETRICH, W. E. A physically based model for the topographic control on shallow landsliding. Water Resources Research, v. 30, n. 4, p. 1153-1171, 1994. DOI: 10.1029/93WR02979.

31. O'LOUGHLIN, C. L. A study of tree root strength deterioration following clear felling. Canadian Journal of Forest Research. v. 4, n. 1, p. 107-113, 1974. DOI :10.1139/x74-016.

32. OHTA, T.; FUKUSHIMA, Y.; SUZUKI, M. Research on runoff from hillsides by one-dimensional transient saturated-unsaturated flow. Journal of the Japanese Forestry Society, v. 65, n. 4, p. 125-134, 1985. DOI: 10.11519/jjfs1953.65.4_125.

33. O'LOUGHLIN, E. M. Prediction of Surface Saturation Zones in Natural Catchments by Topographic Analysis. Water Resources Research, v. 22, n. 5, p. 794-804, 1986. DOI: 10.1029/WR022i005p00794.

34. PACK, R. T.; TARBOTON, D. G.; GOODWIN, C. N. Terrain Stability Mapping with SINMAP, technical description and users guide for version 1.00. Publicação n 4114-0, Terratech Consulting Ltd., Salmon Arm, B.C. Canada 1998. Disponível em: <www.tclbc.com>.

35. PETLEY, D. Global patterns of loss of life from landslides. Geology, 2012. DOI: 10.1130/G33217.1.

36. REGINATTO, G. M. P.; MACCARINI, M.; KOBIYAMA, M.; HIGASHI, R. A .R.; GRANDO, A.; CORSEUIL, C. W.; CARAMEZ, M. L. SHALSTAB application to identify susceptible areas of shallow landslides in Cunha River watershed, Rio dos Cedros city, SC, Brazil. In: International Conference on Geographical Object-Based Image Analysis - GEOBIA 2012, $4^{\text {th }}$, Rio de Janeiro, Anais... Rio de Janeiro, 2012. 6p.

37. ROCHA, H.L.; KOBIYAMA, M.; SILVA, C.G. Análise estatística de chuvas intensas ocorridas nos municípios de Blumenau e Rio dos Cedros, SC, no período de agosto de 2008 a janeiro de 2009. In: Simpósio Brasileiro de Recursos Hídricos, XVIII, 2009, Campo Grande, Anais... Campo Grande: ABRH 14p., 2009.

38. ROERING, J. J.; SCHMIDT, K.; STOCK, J. D.; DIETRICH, W. E.; MONTGOMERY, D. R. Shallow landsliding, root reinforcement, and the spatial distribution of trees in the Oregon Coast Range. Canadian Geotechnical Journal, v. 40, n. 2, p. 237-253, 2003. DOI: 10.1139/t02-113. 
39. ROSSI, L.M.W.; RAPIDEL, B.; ROUPSARD, O.; VILLATORO-SÁNCHEZ, M.; MAO, Z.; NESPOULOUS, J.; PEREZ, J.; PRIETO, I.; ROUMET, C.; METSELAAR, K.. Sensitivity of the landslide model LAPSUS_LS to vegetation and soil parameters. Ecological Engineering, v. 109, p. 249-255, 2017. DOI: 10.1016/j.ecoleng.2017.08.010.

40. SAKALS, M. E.; SIDLE, R. C. A spatial and temporal model of root cohesion in forest soils. Canadian Journal of Forest Research, v. 34, n. 4, p. 950-958, 2004. DOI: 10.1139/x03-268.

41. SANTA CATARINA. Gabinete de Planejamento e Coordenação Geral. Subchefia de Estatística, Geografia e Informática. Atlas de Santa Catarina. Rio de Janeiro: Aerofoto Cruzeiro, 1986. 173 p.

42. SCHAAP, M. G.; LEIJ, F. J.; VAN GENUCHTEN, M. T. Rosetta: a computer program for estimating soil hydraulic parameters with hierarchical pedotransfer functions. Journal of Hydrology, v. 251, n. 3-4, p. 163-176, 2001. DOI: 10.1016/S0022-1694(01)00466-8.

43. SCHMIDT, K. M.; ROERING, J. J.; STOCK, J. D.; DIETRICH, W. E.; MONTGOMERY, D. R.; SCHAUB, T. The variability of root cohesion as an influence on shallow landslide susceptibility in the Oregon Coast Range. Canadian Geotechnical Journal, v. 38, n. 5, p. 995-1024, 2001. DOI: 10.1139/t01-031.

44. SELBY, M. J. Hillslope materials and processes. Oxford: Oxford university press, 1993. 264p. ISBN 978-0198741657

45. SIDLE, R. C. A Conceptual Model of Changes in Root Cohesion in Response to Vegetation Management. Journal of Environmental Quality, v. 20, n. 1, p. 43-52, 1991. DOI: 10.2134/jeq1991.00472425002000010009x.

46. SIDLE, R. C.; OCHIAI, H. Landslides: Processes, Prediction, and Land Use. Washington: AGU, 2006. 307p. ISBN: 9780875903224.

47. STYCZEN, M.E.; MORGAN, R.P.C. Engineering properties of vegetation. In: MORGAN, R.P.C.; RICKSON, R.M. (org.) Slope stabilization and erosion control: A bioengineering approach. Londres: Editora Spoon, 1995, p. 5-58. ISBN 978-0419156307.

48. TAYLOR, D. W. Fundamentals of Soil Mechanics. New York: John Wiley, 1948, 700p. ISBN 978-1258768928.

49. TERZAGHI, K. Mechanism of landslides. In: PAIGE, S. (org.) Applications of Geology to Engineering Practice. New York: Editora Geological Society of America, 1950, p. 83-123p. DOI: 10.1130/Berkey.1950.

50. TSUKAMOTO, Y.; MINEMATSU, H. Evaluation of the effect of deforestation on slope stability and its application to watershed management. IAHS Publication, v.167, p.181-189, 1987.

51. VIANNA, L. F. N.; SOUZA, J. M. Relatório sobre o levantamento dos deslizamentos ocasionados pelas chuvas de novembro de 2008 no complexo do morro do baú municípios de Ilhota, Gaspar e Luiz Alves. Publicação Empresa de Pesquisa Agropecuária e Extensão Rural de Santa Catarina S.A. EPAGRI, 2009, 101p.

52. WATSON, A.; PHILLIPS, C.; MARDEN, M. Root strength, growth, and rates of decay: root reinforcement changes of two tree species and their contribution to slope stability. Plant and Soil, v. 217, n. 1-2, p. 39-47, 1999. DOI: 10.1023/A:1004682509514. 53. WU, T. H.; MCKINNELL III, W. P.; SWANSTON, D. N. Strength of tree roots and landslides on Prince of Wales Island, Alaska. Canadian Geotechnical Journal, v. 16, n. 1, p. 19-33, 1979. DOI: 10.1139/t79-003.

Esta obra está licenciada com uma Licença Creative Commons Atribuição 4.0 Internacional (http://creativecommons.org/licenses/by/4.0/) - CC BY. Esta licença permite que outros distribuam, remixem, adaptem e criem a partir do seu trabalho, mesmo para fins comerciais, desde que lhe atribuam o devido crédito pela criação original. 